\title{
Simulated and Experimental Study of Sediments Sampling Parameters Based on the VOF Method
}

\section{Shudong He}

Hunan University of Science and Technology

YouDuo Peng ( $\nabla$ ydpeng1964@163.com )

Hunan University of Science and Technology https://orcid.org/0000-0003-1917-8522

\section{Yongping Jin}

Hunan University of Science and Technology

Jian Yan

Hunan University of Science and Technology

\section{Buyan Wan}

Hunan University of Science and Technology

\section{Original Article}

Keywords: seabed sediments, sampler, VOF method, computational fluid dynamics, coring volume, coring rate

Posted Date: December 31st, 2020

DOl: https://doi.org/10.21203/rs.3.rs-132647/v1

License: (c) (i) This work is licensed under a Creative Commons Attribution 4.0 International License.

Read Full License 


\title{
Simulated and Experimental Study of Seabed Sediments Sampling Parameters Based on the VOF Method
}

\author{
Shudong He, Youduo Peng*, Yongping Jin, Jian Yan, Buyan Wan \\ National-Local Joint Engineering Laboratory of Marine Resources Exploration Equipment and Safety \\ Technology, Hunan University of Science and Technology, Xiangtan 411201, China. \\ Corresponding author: Youduo Peng E-mail: ydpeng1964@163.com
}

\begin{abstract}
Sediments in the seabed hold vital clues to the study of marine geology, microbial communities and history of ocean life, and the remote operated vehicle (ROV) mounted tubular sampling is an important way to obtain sediments. However, sampling in the seabed is a particularly difficult and complicated task due to the difficulty accessing deep water layers. The sampling is affected by the sampler's structural parameters, operation parameters and the interaction between the sampling tube and sediments, which usually results in low volume and coring rate of sediments obtained. This paper simulated the soft viscous seabed sediments as non-Newtonian Herschel-Bulkley viscoplastic fluids and established a numerical model for the tubular sampling based on the volume of fluid (VOF) method. The influence rules of the sampling tube diameter, drainage area rate, penetration velocity, and sediments dynamic viscosity on coring rate and volume were studied. The results showed that coring volume was negatively correlated with all the parameters except the sampling tube diameter. Furthermore, coring rate decreased with increases in penetration velocity, drainage area rate, and sediments dynamic viscosity. The coring rate first increased and then decreased with increasing of the sampling tube diameter, and the peak value was also influenced by penetration velocity. Then, based on the numerical simulation results, an experimental sampling platform was set up and real-world sampling experiments were conducted. The simulation results tallied with the experimental results, with a maximum absolute error of only $4.6 \%$, which verified that the numerical simulation model accurately reflected real-world sampling. The findings in this paper can provide a theoretical basis for facilitating the optimal design of the geometric structure of the seabed sediments samplers and the parameters in the sampling process.
\end{abstract}

Key words: seabed sediments; sampler; VOF method; computational fluid dynamics; coring volume; coring rate

\section{Introduction}

Deep-sea sediments hold evolutionary records of the oceanic environment, records of great significance for scientific fields investigating marine sedimentary processes, structural evolution, paleoceanography, paleomagnetism, seabed mineral resource exploration, and history of marine life. However, the acquisition of original samples from deep-sea sediments is completely dependent on advanced seabed sediments collection methods and technical equipment [1-4]. Among them, the ROV-mounted tubular sampling is one of the important ways to obtain seabed sediments. However, sampling in the seabed is a particularly difficult and complicated task due to the difficulty accessing deep water layers. The sampling is affected by the sampler's structural parameters, operation parameters and the interaction between the sampling tube and sediments, which usually results in low volume and coring rate of sediments obtained [5-8]. For example, Emery and Dietz et al. [9] found that the sediments entering the tube was compressed to about $50 \%$ of the penetration depth by measuring the sampling rate of an open gravity sampler. Therefore, it is particularly important to study the influence rules of key parameters such as the sampling tube diameter, drainage area rate, penetration velocity, and sediments dynamic viscosity on coring volume and rate based on the dynamic sampling process, which can provide a basis for the design of samplers with high sampling volume and coring rate.

Many researchers ignored the high pressure in seabed, and they used the pipe pile theory to assume that the sampling process of deep-sea sediments was approximately equivalent to the process of pipe piles driving into soft clay, and the sediments sampling process was theoretically modeled and analyzed. For example, Carret et al. [10] regarded the sampling process as the expansion of a cylindrical hole in soil. Axisymmetric elastoplastic theory was used to study the change characteristics of stress and pore water stress during pile sinking in viscous soil, and a change rule for the stress field with depth was obtained. Tatsvnovi [12] regarded the soil plug as a series of spring units connected in series with mass points using stress wave theory, and carried out dynamic and static mechanical analyses of the pile penetration process. L.C. Skinner et al. [13] established a mathematical model of the sampling process based on the principle of soil mechanics, and analyzed the effects of a gravity corer and a piston sampler on the coring volume and rate of marine sediments samples.

Based on the principle of soil mechanics, the study of sampling process by using pipe pile theory lacks the understanding of the physical mechanism determining sediments strain and stress characteristics in the sampling process, and sampling dynamic process is not visually clear. Therefore, some researchers have turned to numerical methods to analyze the coring process. For example, Chopra et al. [14] used the finite element method to establish a time-dependent, large-deformation 
consolidation analysis. They believed that the sediments followed the revised Cambridge model, and the principle of effective stress was used to derive the large deformation finite element consolidation equations, which were later applied to simulate the sampling process. Randolph et al. [15] conducted a one-dimensional simplified analysis of soil plugs of pipe piles during penetration, discussing the soil plug problem only in drained conditions and not in undrained conditions. Zhou et al. [16] applied a nonlinear finite element analysis method to establish a two-dimensional axisymmetric finite element model of the contact between the sampling tube and the sediments, and selected the Drucker-Prager elastoplastic model to simulate the sediments. By assessing disturbance to the sediments during the sampling process, the results confirmed that a tubular sampler would cause the shortening of sediments samples. However, this method also ignored the effect of hydrostatic pressure. Qin et al. [17] proposed a numerical method for simulating gravity coring in which the sediments model was a modified Drucker-Prager constitutive model. They established a three-dimensional finite element model based on ABAQUS, and the sampling effect was analyzed using the Euler-Lagrange coupling method. Obvious phenomena of sample shortening were captured in this model. Guo et al. [18] used the discrete element model (DEM) to simulate the clogging of soil inside a large-diameter pipe pile, comprehensively simulating the interactions between the soil particles and between the soil particles and the pipe pile. The influence of parameters such as the length of the soil column, inner diameter of the pile was studied, but the soil did not conform to the mechanical characteristics of seabed sediments.

In the above-mentioned researches, the elastic-plastic model based on the principle of soil mechanics was usually used to characterize the seabed sediments, which is different from the actual situation of deep-sea environment which is characterized by ultrahigh pressure. Moreover, the influences of hydrostatic pressure and sampling velocity on the coring volume and rate were ignored in research processes. In this paper, the sampling process of sediments was studied from the perspective of fluid mechanics, and the influence rules of key parameters such as the sampling tube diameter, drainage area rate, penetration velocity, sediments dynamic viscosity on coring rate and volume were studied. The simulation results tallied with the experimental results, which proved that this method is more suitable for the actual seabed sampling. The findings in this paper can provide a theoretical basis for facilitating the optimal design of the geometric structure of the seabed sediments samplers and the parameters in the sampling process.

\section{Methodology}

The sampling device, as an important part of the sampler, is used to collect deep-sea sediments. The studied sampling device's major components included a handle, a sampling tube, a high-pressure valve, a gas-tight coupler, and a piston. A number of holes were evenly spaced around the proximal end of the sampling tube for drainage. The outer side of the top of the sampling tube was connected via threading with the gas-tight coupler, tightening onto an O-ring to guarantee the seal and ensure constant pressure retaining the sediments once sampling was completed, until being fixed to the pressure-retaining cylinder. The sampler is mounted on an ROV. When the sampler reaches the sampling point, the mechanical arm grabs the handle of the sampling device and inserts it vertically into the sediments with a certain velocity. Then, the sampling device is pulled vertically upward and is fixed to the sampler until it is locked and sealed. In order to meet the requirements of modeling, the sampling tube length is marked as L, the sampling tube diameter as D, and the drain hole diameter as d, as shown in Fig. 1.

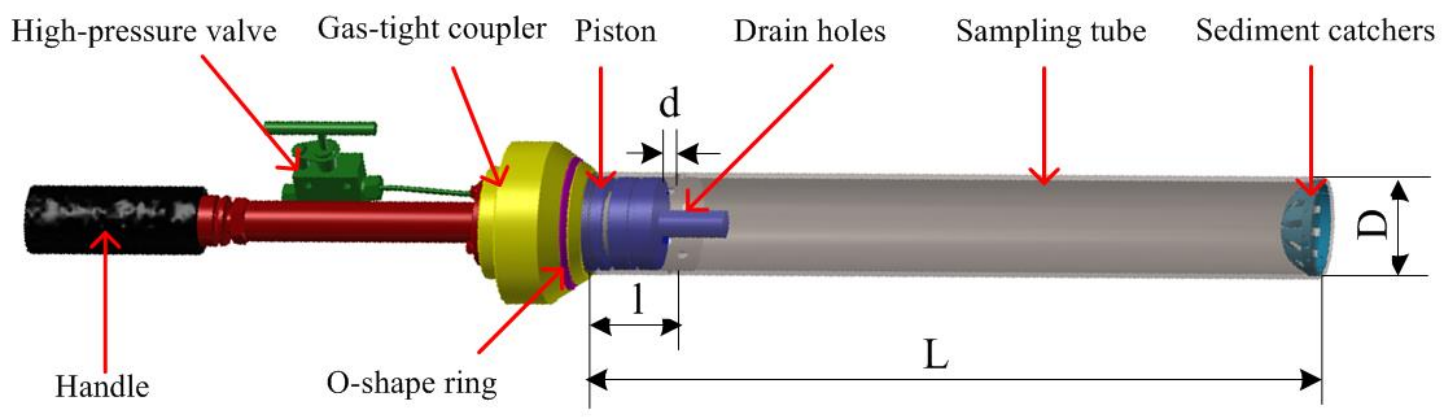

Fig. 1 Structure of the sampling device

\subsection{Multiphase model}

In order to simplify the model, it is imperative to make reasonable assumptions. The specific 
assumptions are as follows:

(1) The sediments and water are not mixed with each other during the sampling process because the velocity during penetration is relatively low (According to the requirements of the on-site ROV's mechanical arm, the penetration velocity is usually set at less than $200 \mathrm{~mm} / \mathrm{s}$.), in each controlled volume, the sum of the volume fractions of water and sediments is 1 ;

(2) The flow of sediments and water in the tube is continuous during the sampling process;

(3) Any changes in temperature or sediments water content have no influence on the sediments dynamic viscosity;

(4) The thickness of the sampling tube wall is zero and the sampling tube sediments catchers have no influence on sampling.

The continuity equation is as follows:

$$
\frac{1}{\rho_{\mathrm{q}}}\left[\frac{\partial}{\partial t} \boldsymbol{\alpha}_{q} \rho_{q} \doteq \nabla \boldsymbol{\alpha}_{q} \rho_{q} \vec{v}_{q} \fallingdotseq S_{\alpha_{q}}+\sum_{p=1}^{n}\left(\dot{m}_{p q}-\dot{m}_{q p}\right)\right]
$$

Where $\rho_{\mathrm{q}}$ is the physical density of phase $\mathrm{q} ; \vec{v}_{q}$ is the velocity of phase $\mathrm{q} ; \dot{m}_{p q}$ is the mass transfer from phase $\mathrm{q}$ to $\mathrm{p} ; \dot{m}_{q p}$ is the mass transfer from phase $\mathrm{p}$ to $\mathrm{q}$; and $S_{\alpha_{q}}$ is the source item with a default value of zero.

The basic phase volume fraction is calculated with the constraint that the sum of the volume fractions of all phases is 1 without solving the volume fraction equation:

$$
\sum_{q=1}^{n} \alpha_{\mathrm{q}}=1
$$

Unit density:

$$
\rho=\alpha_{2} \rho_{2}+\mathbf{Q}-\alpha_{2} \bar{\rho}_{1}
$$

Where the seawater density is $\rho_{1}$. In this paper, $\rho_{1}=1.06 \times 10^{3} \mathrm{~kg} / \mathrm{m}^{3}$ and $\rho_{2}$ is the sediments density with where $\rho_{2}=1.6 \times 10^{3} \mathrm{~kg} / \mathrm{m}^{3}$.

Momentum equation:

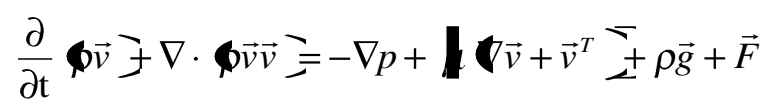

Where $\mu$ is the dynamic viscosity; and $\vec{F}$ is the source item of the momentum equation caused by surface tension and wall adhesion.

$$
\frac{\partial \varepsilon}{\partial \mathrm{t}}+\vec{u}_{i} \frac{\partial \varepsilon}{\partial x_{i}}=\frac{\partial}{\partial x_{i}}\left[\sigma_{\varepsilon} \mu_{e f f} \frac{\partial \varepsilon}{\partial x_{j}}\right]+\rho c_{1} S_{\varepsilon}-\rho c_{2 \varepsilon} \frac{\varepsilon^{2}}{k+\sqrt{v \varepsilon}}
$$

Where, $\mu_{\text {eff }}=\mu_{1}+\mu_{\mathrm{t}}$

$$
\begin{aligned}
& c_{1}=\max \left[0.43, \frac{\eta_{1}}{\eta_{1}+5}\right] \\
& \eta_{1}=S_{\varepsilon} \frac{\mathrm{k}}{\varepsilon} \\
& S_{\varepsilon}=\sqrt{2 S_{\mathrm{ij}} S_{i j}}
\end{aligned}
$$

Assuming that the penetration depth of the sampling tube into the sediments is $L$, the height of the sediments entering the sampling tube is $H$, and the coring volume is $Q$, then:

$$
Q=\frac{1}{4} \pi D^{2} H
$$

At the same time, in order to further evaluate the sampling performance of the sampler, the concept of coring rate is introduced. The coring rate is $\lambda$ : 


$$
\lambda=\frac{H}{L} \times 100 \%
$$

The coring rate $\lambda$ is an important index of deep-sea sediments sampling equipment. The larger $\lambda$ is, the better the sampling performance is; the lower $\lambda$ is, the worse the sampling performance is. Therefore, the research focus of this paper was to determine how to effectively increase the coring volume and rate of the sampler.

\subsection{Computational fluid dynamics model and grid layout}

Before the establishment of a computational fluid dynamics model, the sampling device is simplified to a round tube with a closed upper end and an open lower end. The velocity during penetration of the sampling tube can be set by writing user-defined function (UDF) programs. Considering that the locations of the drain holes are not symmetrical, the model includes the entire cylindrical computational domain. Setting the criterion for the computational domain size serves to minimize the impact of blocking. The entire computational domain is divided into seawater area and sediments area. The settings and parameters of the computational domain are shown in Fig. 2:

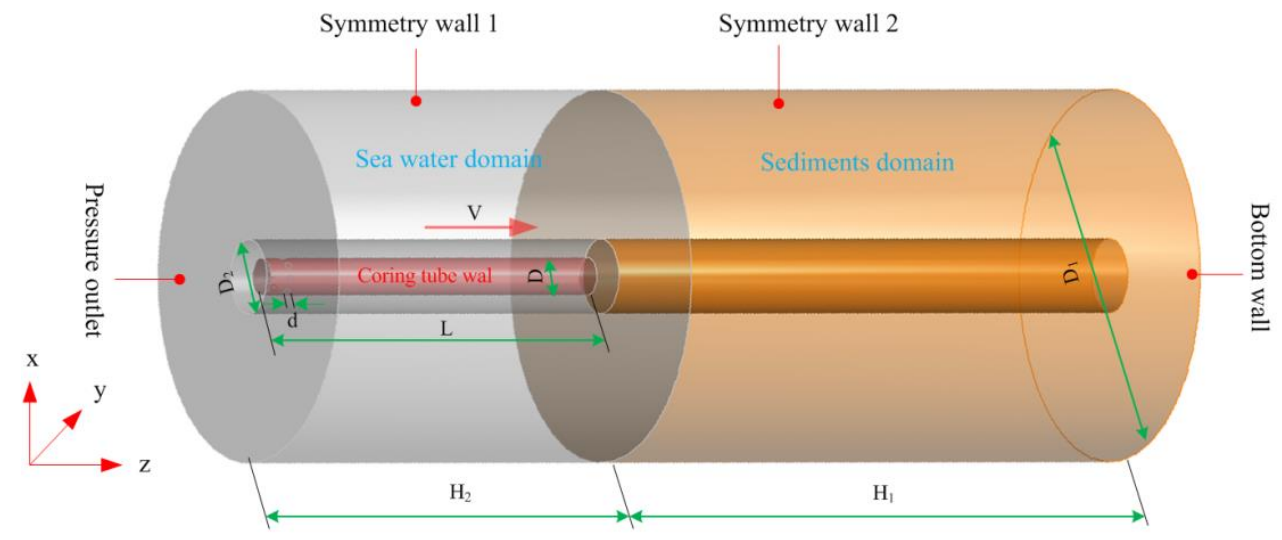

Fig. 2 3D computational fluid dynamics model of sampling

The grid quality directly affects the accuracy of the computational results. In order to obtain more accurate computational results while also reducing computational costs, the structural grid was adopted, which is mainly tetrahedron. However, because higher numbers of the grid cell benefit computational accuracy but also increase computational cost, an acceptable degree of error must be determined. In order to find a balance between error and cost, it is necessary to verify the grid independence to determine the grid size. Under the conditions of sampling tube length $\mathrm{L}=500 \mathrm{~mm}$, sediments viscosity $\eta=10 \mathrm{~kg} / \mathrm{m} \cdot \mathrm{s}$ and the penetration velocity $\mathrm{v}=20 \mathrm{~mm} / \mathrm{s}$, the grid model with cell number of 958703,1873831 and 2748026 were calculated. Additionally, coring rates of different diameter sampling tubes were calculated. It can be seen from Fig. 3 that there was a significant difference between the grid model with 958703 and 1873831 cells, while the curves resulting from the models with 1873831 and 2748026 cells were essentially the same. Therefore, to balance computational costs and the accuracy of the numerical results, the model selected for this paper had 1873831 cells, as shown in Fig. 4. 


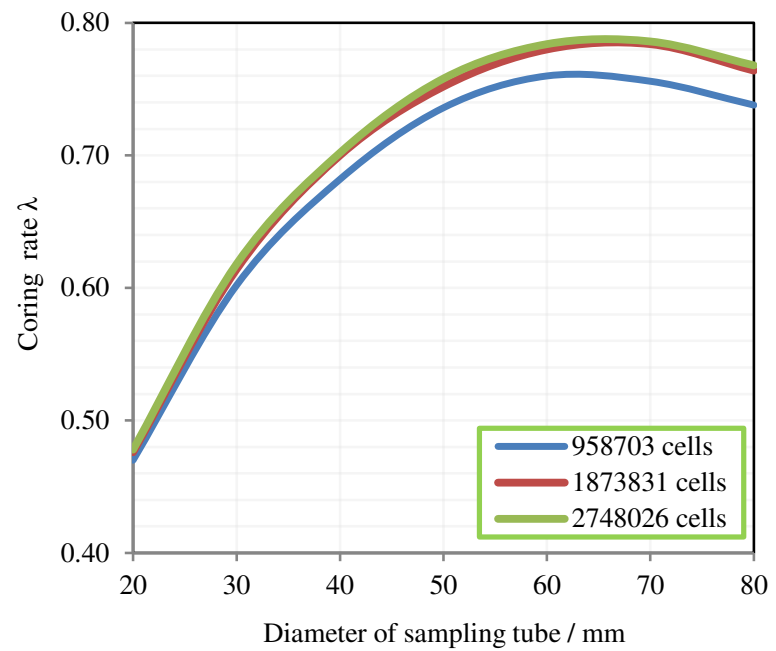

Fig. 3 Coring rates under different grid models

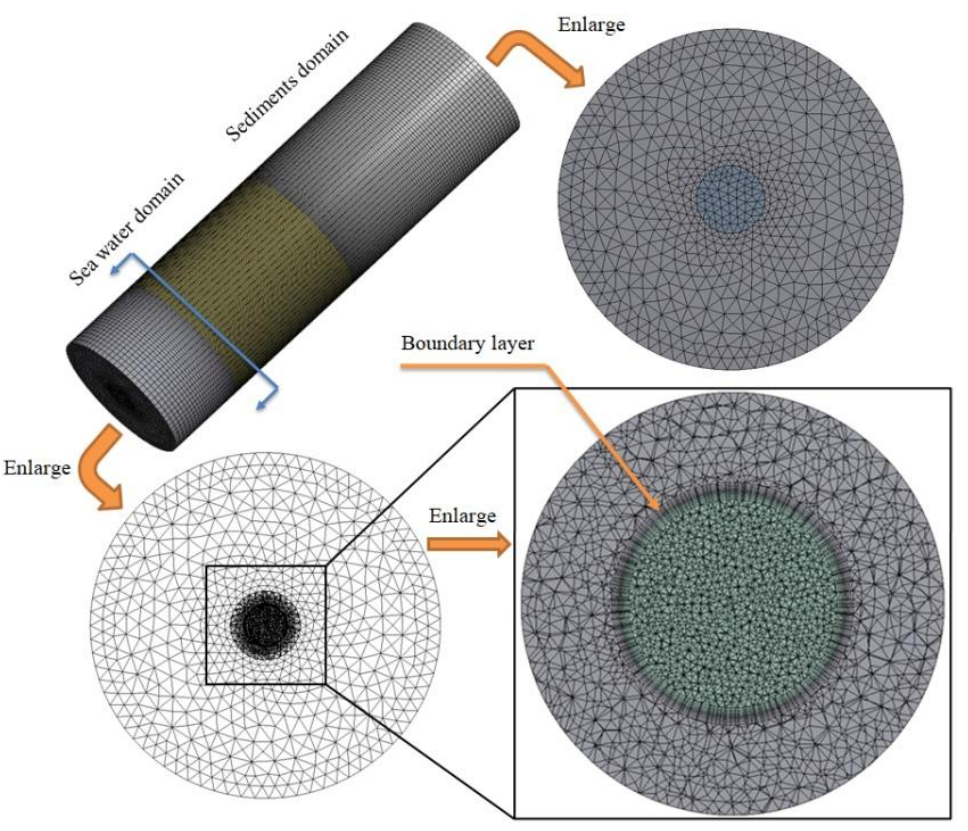

Fig. 4 Three grid models of sampling

\subsection{Computational parameters and boundary conditions}

The multiphase model and the realizable k- $\varepsilon$ turbulence model were used to simulate the flow field in the computational domain. The calculation uses 3D single precision, and the dynamic grid change is controlled by a dynamic layering method, which activates the size function control to prevent the occurrence of excessively distorted grids during the calculation process. The convection term is discretized by a first order upwind scheme that easily converges. The pressure solver was also used, and the PISO algorithm was applied for pressure-velocity coupling.

Outlet boundary conditions: the boundary conditions of pressure outlet were adopted, with a gauge pressure of zero.

Wall boundary conditions: the lower boundary of the computational domain adopted rigid boundary, and for the cylindrical surface of the computational domain a symmetric boundary was adopted.

\subsection{Settings of parameters}

\subsubsection{Sampling tube diameter}

Laboratory sampling experiments and research data have shown that coring volume and rate are related to the sampling tube diameter. To select the sampling tube diameter, the index requirements must be met, such as the coring volume requirements and the weight requirements of the sampler for 
ROV on-board operation. In this paper, the sampling tube diameter was set to within the range of 20 $\mathrm{mm}$ to $80 \mathrm{~mm}$ to best meet the research goals.

\subsubsection{Penetration velocity}

Literature [12] shows that coring volume and rate are affected by penetration velocity. Therefore, the penetration velocity should be chosen to maximize sampling performance. Too high a sampling speed velocity during penetration may hinder the flow of water in the sampling tube or exceed the capacity of the drain holes, and the upper surface of the sediments in the sampling tube may generate water pressure which will reduce the coring rate. At the same time, according to the sampling operation requirements of the on-site ROV's mechanical arm, the penetration velocity is usually set at less than $200 \mathrm{~mm} / \mathrm{s}$. In order to study the influence of the penetration velocity on coring volume and rate, the simulated velocities of penetration ranged from $20 \mathrm{~mm} / \mathrm{s}$ to $200 \mathrm{~mm} / \mathrm{s}$ in this paper.

\subsubsection{Drainage area rate}

In the actual sampling process, if the drainage from the sampling tube is not smooth or becomes completely closed, the flow of water in the sampling tube will be blocked, and the upper surface of sediments in the sampling tube may generate water pressure which will reduce the sampling rate. In order to overcome this "hydraulic effect", drain holes with a certain diameter are arranged around the upper circumference of the sampling tube to reduce the hydrostatic pressure on the upper surface of the sediments. In this paper, drain holes for the upper circumference of the sampling tube were proposed, and the number and the diameter of drain holes must meet the requirements of the sampling tube. Therefore, the drainage area rate of the fluid in the sampling tube was introduced, and is defined as follows:

$$
\beta=\frac{S_{\text {in }}}{S_{\text {out }}}
$$

Where $S_{\text {in }}$ is the total inlet area of the sampling tube; and $S_{\text {out }}$ is the outlet area of the sampling tube.

$$
S_{\text {in }}=\frac{1}{4} \pi D^{2}
$$

Where $\mathrm{D}$ is the sampling tube diameter.

$$
S_{\text {in }}=N \times \frac{1}{4} \pi \mathrm{d}^{2}
$$

Where $N$ is the number of drain holes $(N=8)$; and d is the drain hole diameter.

Under the same tube diameter condition, setting $0<\beta \leq 12$, the influence of different drainage area rates on the coring volume and rate was studied.

\subsubsection{Sediments dynamic viscosity}

Previous research data has shown that the sediments located on the seabed surface has a high water content and high viscosity, which conforms to the characteristics of a non-Newtonian fluid. The Herschel-Bulkley model is one of the simplest viscoplastic models for non-Newtonian fluids. The model is described using the following parameters:

$$
\begin{cases}\dot{\gamma}=0, & |\tau| \leq \tau_{0} \\ |\tau|=\tau_{0}+K|\dot{\gamma}|^{\mathrm{n}} & |\tau|>\tau_{0}\end{cases}
$$

Where $\tau_{0}$ is the yield stress; $\dot{\gamma}$ is the shear strain rate; $\mathrm{K}$ is the consistency coefficient; and $\mathrm{n}$ is the shear-thinning index. The above formula is simplified to $n=1$. The shear stress changes linearly with shear strain rate, thus $K$ is the dynamic viscosity $\eta$.

In the experiments part of section 4 , the sediments dynamic viscosity was measured, and the value was within $100 \mathrm{~kg} / \mathrm{m} \cdot \mathrm{s}$ under different temperature conditions. The sediments dynamic viscosity is directly related to its water content and the temperature and pressure of the environment, so the sediments at different depths and in different sea areas will have different dynamic viscosities. Therefore, this paper set the sediments dynamic viscosity to range from $10^{-2}$ to $10^{2} \mathrm{~kg} / \mathrm{m} \cdot \mathrm{s}$ to study the influence of dynamic viscosity on coring volume and coring rate. 
The specific calculation parameters of the model are shown in Table 1:

Table 1 Parameters of computational fluid dynamics model

\begin{tabular}{|c|c|c|}
\hline Types & Parameters & Value \\
\hline \multirow{5}{*}{ Structure } & Sampling tube length $\mathrm{L} / \mathrm{mm}$ & 500 \\
\hline & Sampling tube diameter $\mathrm{D} / \mathrm{mm}$ & $20 \sim 80$ \\
\hline & Drain hole diameter $\mathrm{d} / \mathrm{mm}$ & $2 \sim 20$ \\
\hline & Location of the drainage hole $\mathrm{I} / \mathrm{mm}$ & 20 \\
\hline & Drainage area rate $\beta$ & $0 \sim 12$ \\
\hline \multirow{6}{*}{$\begin{array}{l}\text { Computational fluid } \\
\text { dynamics model }\end{array}$} & Length of sea area $\mathrm{H} 2 / \mathrm{mm}$ & $2 \mathrm{~L}$ \\
\hline & Length of sediments $\mathrm{H} 1 / \mathrm{mm}$ & $3 \mathrm{~L}$ \\
\hline & Diameter of calculation area D1/mm & $10 \mathrm{D}$ \\
\hline & Diameter of dynamic mesh area D2/mm & $5 \mathrm{D}$ \\
\hline & Penetration velocity $\mathrm{v} /(\mathrm{mm} / \mathrm{s})$ & $20 \sim 200$ \\
\hline & Sediments dynamic viscosity $\eta / \mathrm{kg} /(\mathrm{m} \cdot \mathrm{s})$ & $10^{-2} \sim 10^{2}$ \\
\hline
\end{tabular}

\section{Results and discussion}

The sampling tube length (L), diameter (D), and drain hole diameter (d) will affect the sediments entering the tube, which needs to overcome its own viscous resistance, interfacial surface tension, and water resistance during sampler penetration. When sampling is finished, the height of sediments that has entered the tube can be clearly observed, and the height of the sediments in the sampling tube was always less than the sampling tube's penetration depth, as shown in Fig. 5. In order to further study the relationship between sampling efficiency and the influential parameters, this paper studied the influence of different velocities of penetration, different inner diameters of the sampling tube, different drainage area rate, and different dynamic viscosities of sediments on coring volume and coring rate.

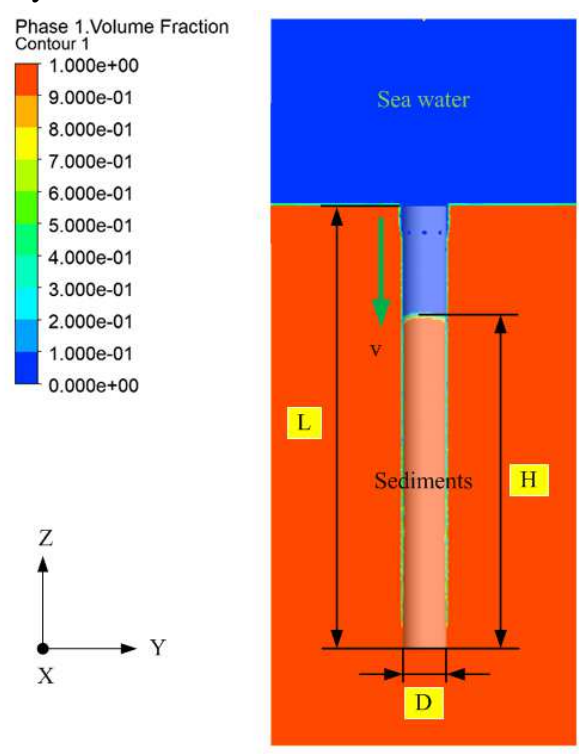

Fig. 5 Sketch map of sampling

\section{1 Influence of the sampling tube diameter}

In this section, the study on influence rules of the sampling tube diameter on the coring volume and coring rate is reported and discussed. For this examination, the length of the sampling tube was $500 \mathrm{~mm}$, the viscosity of the sediments was $10 \mathrm{~kg} / \mathrm{m} \cdot \mathrm{s}$, the drain holes diameter was $5 \mathrm{~mm}$, the sampler diameter ranged from 20 to $80 \mathrm{~mm}$, and six different velocities of penetration were used. Fig. 6 shows the coring volume increased linearly with increases in sampling tube diameter. The lower the penetration velocity, the more obvious the increasing trend in coring volume. Fig. 7 shows the coring rate first increased and then decreased with increases in the sampling tube diameter. When the penetration velocity was $200 \mathrm{~mm} / \mathrm{s}$ and the sampling tube diameter was $40 \mathrm{~mm}$, the coring rate was 
about 0.33 . When the penetration velocity was $20 \mathrm{~mm} / \mathrm{s}$ and the sampling tube diameter was $70 \mathrm{~mm}$, the coring rate was around 0.8 .

The comparison between Fig. 6 and Fig. 7 shows that the changing trends of the sampling tube diameter on the coring volume and rate are completely different. Increasing the sampling tube diameter can improve the coring volume, but the coring rate first increases and then decreases, indicating there is an inflection point at which an optimal coring rate is achieved. When designing the sampling tube, increasing the sampling tube diameter can increase the sampling volume, but an unlimited increase in the sampling tube diameter means an increase in the weight of the sampler, which is definitely not desirable for ROV with a weight limit on the sampler. Therefore, under the condition of a known penetration velocity, a reasonable sampling tube diameter is an important guarantee for obtaining samples with a high coring rate.

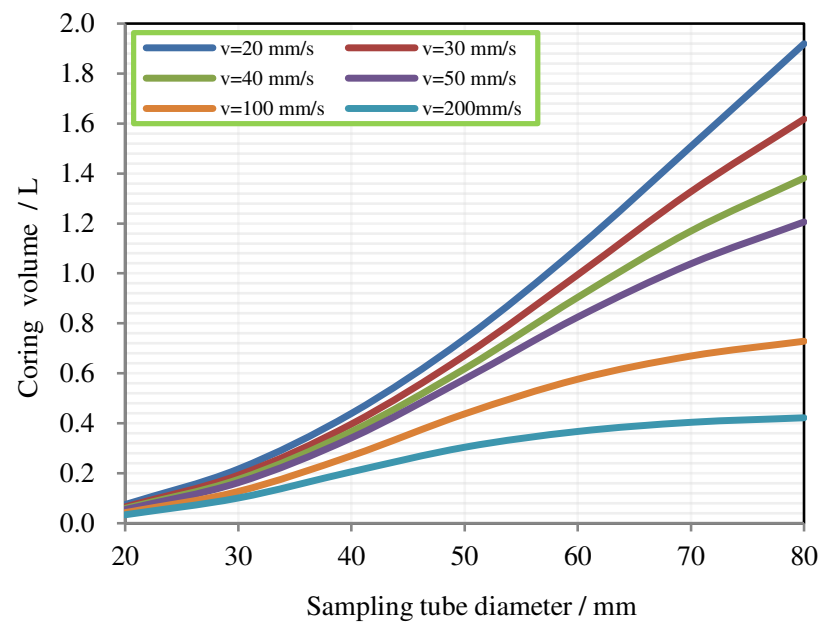

Fig. 6 The influence curve of the sampling tube diameter on the coring volume

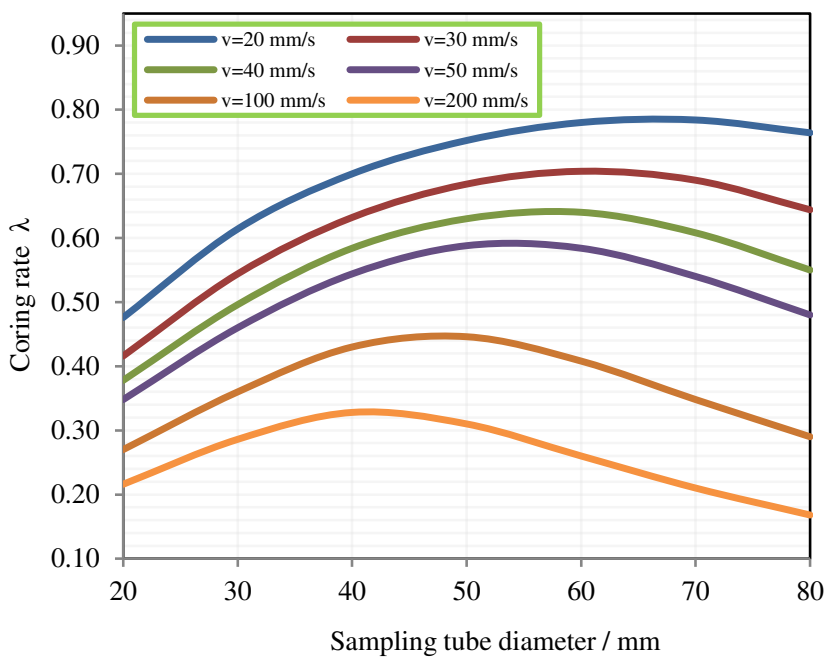

Fig. 7 The influence curve of the sampling tube diameter on the coring rate

\section{2 Influence of drainage area rate}

Drainage area rates determine the flow of the water in the sampling tube and whether it can be drained smoothly or not. Therefore, in this section, numerical simulations were conducted for drainage area rates of $1,2,3,4,6,8$, and 12 , and the influence rules of different drainage area rates on coring volume and rate were assessed. For these simulations, the sampling tube length was $500 \mathrm{~mm}$, sediments viscosity was $10 \mathrm{~kg} / \mathrm{m} \cdot \mathrm{s}$, and the penetration velocity was $100 \mathrm{~mm} / \mathrm{s}$.

Fig. 8 shows the influence rules of drainage area rate of the sampling tube on the coring volume. Under the condition of the sampling tube diameters of $20 \mathrm{~mm}, 30 \mathrm{~mm}, 40 \mathrm{~mm}$, the coring volume remains constant with the drainage area rate. While, under the condition of the sampling tube diameters of $50 \mathrm{~mm}, 60 \mathrm{~mm}, 70 \mathrm{~mm}, 80 \mathrm{~mm}$, when the drainage area rate was less than or equal to 3 , the coring volume remained basically unchanged. When the drainage area rate was greater than 3 , the 
coring volume decreased with increasing drainage area rate, this trend became more pronounced as the sampling tube diameter increased. Fig. 9 shows the influence of drainage area rate of the sampling tube on the coring rate. When the drainage area rate was less than or equal to 3 , the coring rate remained basically unchanged; when the drainage area rate was greater than 3 , the coring rate decreased with increasing drainage area rate. This trend became more pronounced as the sampling tube diameter increased. Therefore, both coring volume and rate are related to drainage area rate.

This important finding showed that as long as the inlet area was less than or equal to 3 times the outlet area, drainage would not be hindered and optimal sampling could be achieved, providing an important reference for the design of drainage discharge in samplers.

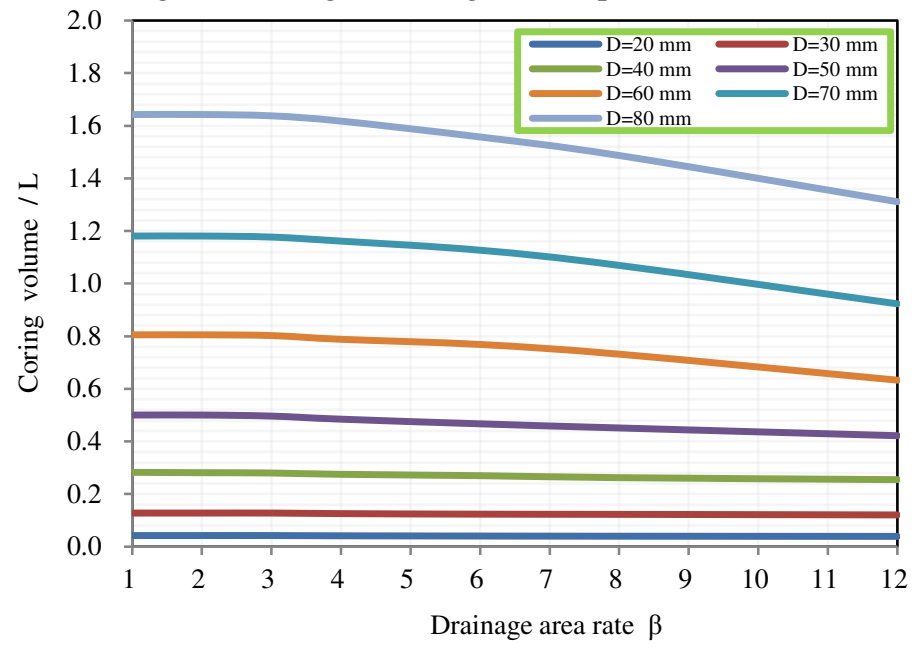

Fig. 8 The influence curve of the drainage area rate on the coring volume

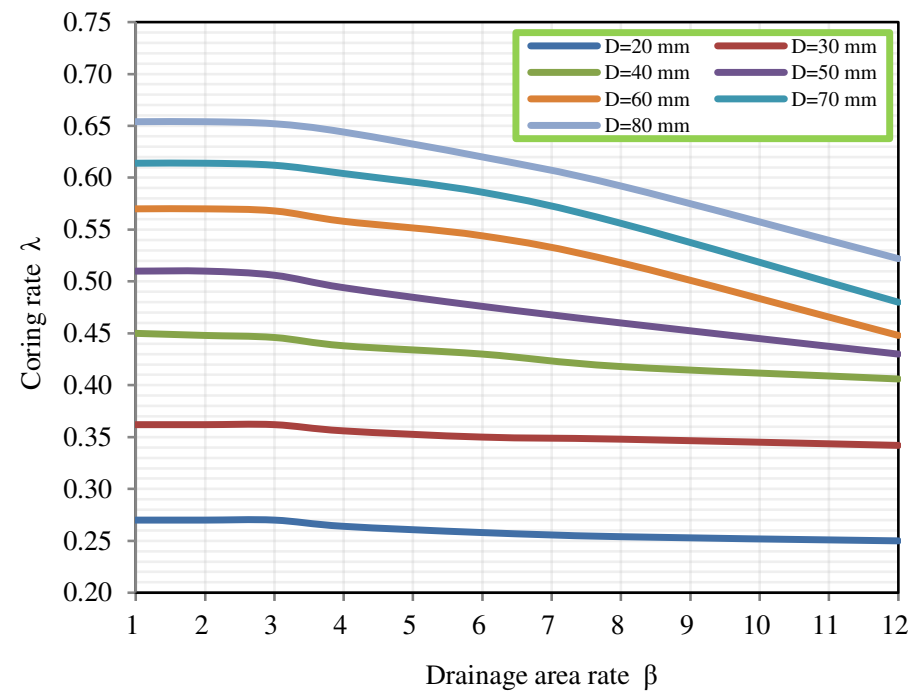

Fig. 9 The influence curve of the drainage area rate on the coring rate

\section{3 Influence of the penetration velocity}

The sediments sampling process is regarded as the flow of fluid in a tube. Then, the penetration velocity directly affects surface tension, wall adhesion, and fluid friction loss, thus affecting the coring volume and coring rate according to the relevant knowledge of fluid mechanics. Therefore, the influence rules of different velocities of penetration on the coring volume and rate were examined in this study. Numerical simulations were carried out for the penetration velocities of $20 \mathrm{~mm} / \mathrm{s}, 30 \mathrm{~mm} / \mathrm{s}$, $40 \mathrm{~mm} / \mathrm{s}, 50 \mathrm{~mm} / \mathrm{s}, 100 \mathrm{~mm} / \mathrm{s}$, and $200 \mathrm{~mm} / \mathrm{s}$. For these calculations, the sampling tube length was 500 $\mathrm{mm}$, the drain holes diameter was $5 \mathrm{~mm}$, and the sampling tube diameter was $40 \mathrm{~mm}$.

When the sediments dynamic viscosity was $1,10,100(\mathrm{~kg} / \mathrm{m} \cdot \mathrm{s})$, the coring volume and rate decreased with increasing penetration velocity, and the trend of decrease was basically the same. When the sediments dynamic viscosity was $0.1,0.01(\mathrm{~kg} / \mathrm{m} \cdot \mathrm{s})$, the coring volume and rate first 
remained unchanged and then gradually decreased with the increasing of penetration velocity. This inflection point is related to the sediments dynamic viscosity.

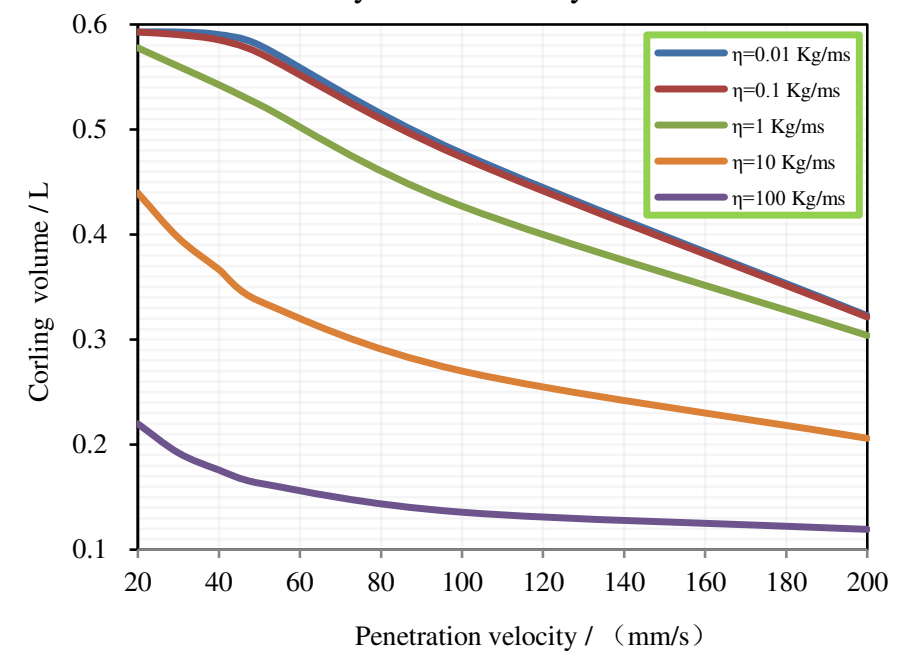

Fig. 10 The influence curve of the penetration velocity on the coring volume

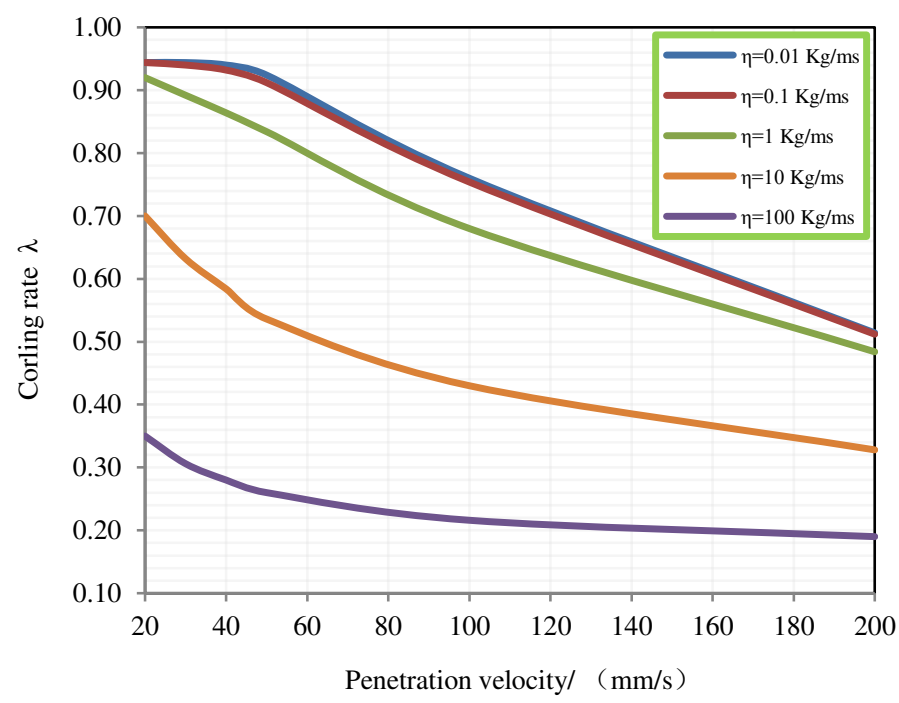

Fig. 11 The influence curve of the penetration velocity on the coring rate

\section{4 Influence of sediments dynamic viscosity}

From the section 3.3, the sediments sampling process is regarded as the flow of fluid in a tube. Similarly, the sediments dynamic viscosity also affects surface tension, wall adhesion, and fluid friction loss, thus affecting the coring volume and coring rate according to the relevant knowledge of fluid mechanics. This section, the influence rules of different sediments dynamic viscosities ( 0.01 to $100 \mathrm{~kg} / \mathrm{m} \cdot \mathrm{s}$ ) on coring volume and rate under different the velocities of penetration were studied.

Fig. 12 and 13 show the influence rules of the different sediments dynamic viscosities on the coring volume and rate, respectively. For these simulations, the sampling tube length was $500 \mathrm{~mm}$, the drain holes diameter was $5 \mathrm{~mm}$, and the sampling tube diameter was $40 \mathrm{~mm}$. When the viscosity was less than 0.1 , the decreasing trend observed in coring volume and coring rate as viscosity increased was not obvious. It can be seen from the figures, that when the dynamic viscosity was 0.1 and 0.01 , the corresponding curves of coring volume and rate coincided. When the viscosity was $1,10,100$ ( $\mathrm{kg} / \mathrm{m} \cdot \mathrm{s}$ ), the decreasing trends in coring volume and rate as viscosity increased were obvious. Before sampling, it was necessary to measure or estimate the characteristic parameters of sediments, such as dynamic viscosity, so as to facilitate the optimal design of structural parameters of the sampler using realistic values. 


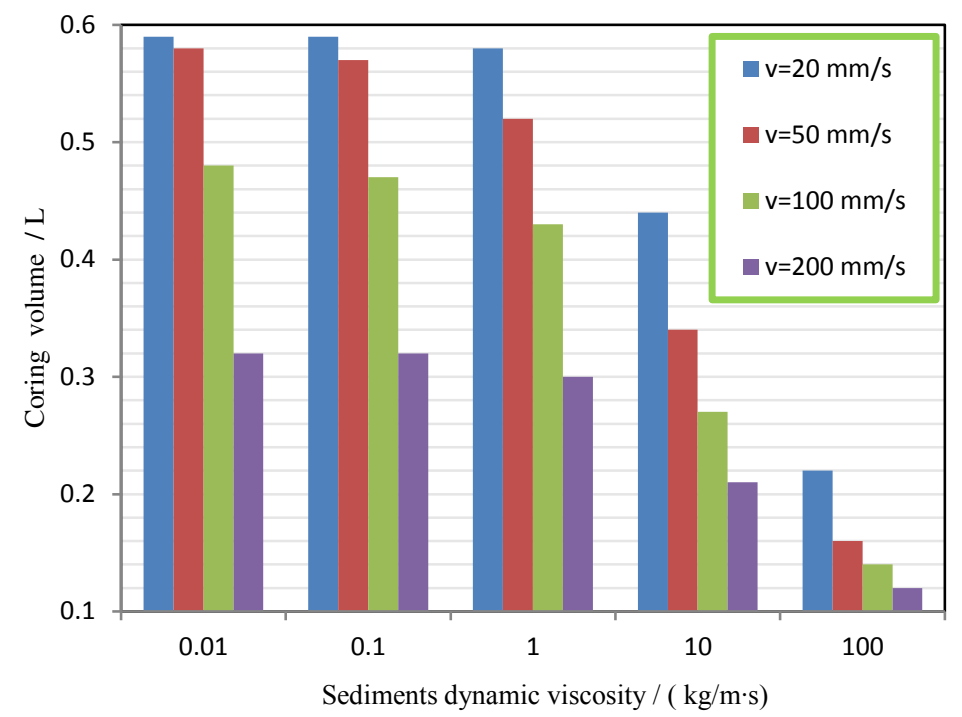

Fig.12 The influence curve of the sediments dynamic viscosity on the coring volume

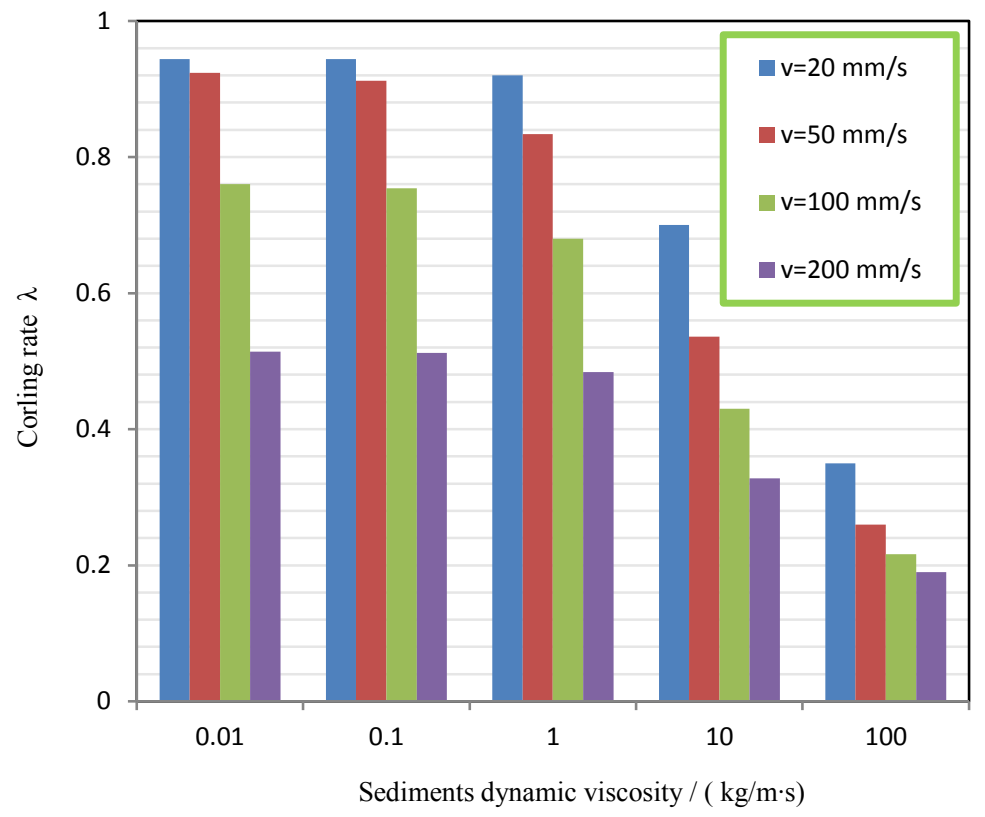

Fig. 13 The influence curve of the sediments dynamic viscosity on the coring rate

\section{Experimental study}

In this section, in order to verify the correctness of the model and the results, a sampling experimental platform was set up to conduct the sampling experiments on the basis of the simulation results analyzed in the previous section.

\subsection{Experimental principles}

According to the simulation results, when the drainage area rate was less than or equal to 3 in the water environment, smooth drainage can be ensured, thus ignoring the influence of drainage pressure. Since the order of magnitude of the dynamic viscosity of air is $10^{-5}$, which is much smaller than that of water $\left(10^{-3}\right)$, it is feasible to use the laboratory air environment to replace the water environment for sampling experiments as long as the drainage area rate is less than or equal to 3 . Then, a sampling experimental platform was set up for sampling experiments.

The platform is shown in Fig. 14, its major components include: the platform body, a tank, an operational platform, control assembly, and hydraulic and electrical control piping. The platform body comprised a base, a circular hydraulic oil cylinder, a displacement sensor, a proximity switch, fixed 
components, etc. The control components included velocity controls, a hydraulic oil tank, a three-phase motor, a pressure gauge, etc. The operation platform comprised an operation cabinet body, a touch panel (data acquisition computer and software), and relevant operational buttons. The sampling assembly was made up of a transparent sampling tube and piston, and an O-ring to create a seal between the piston and the sampling tube.

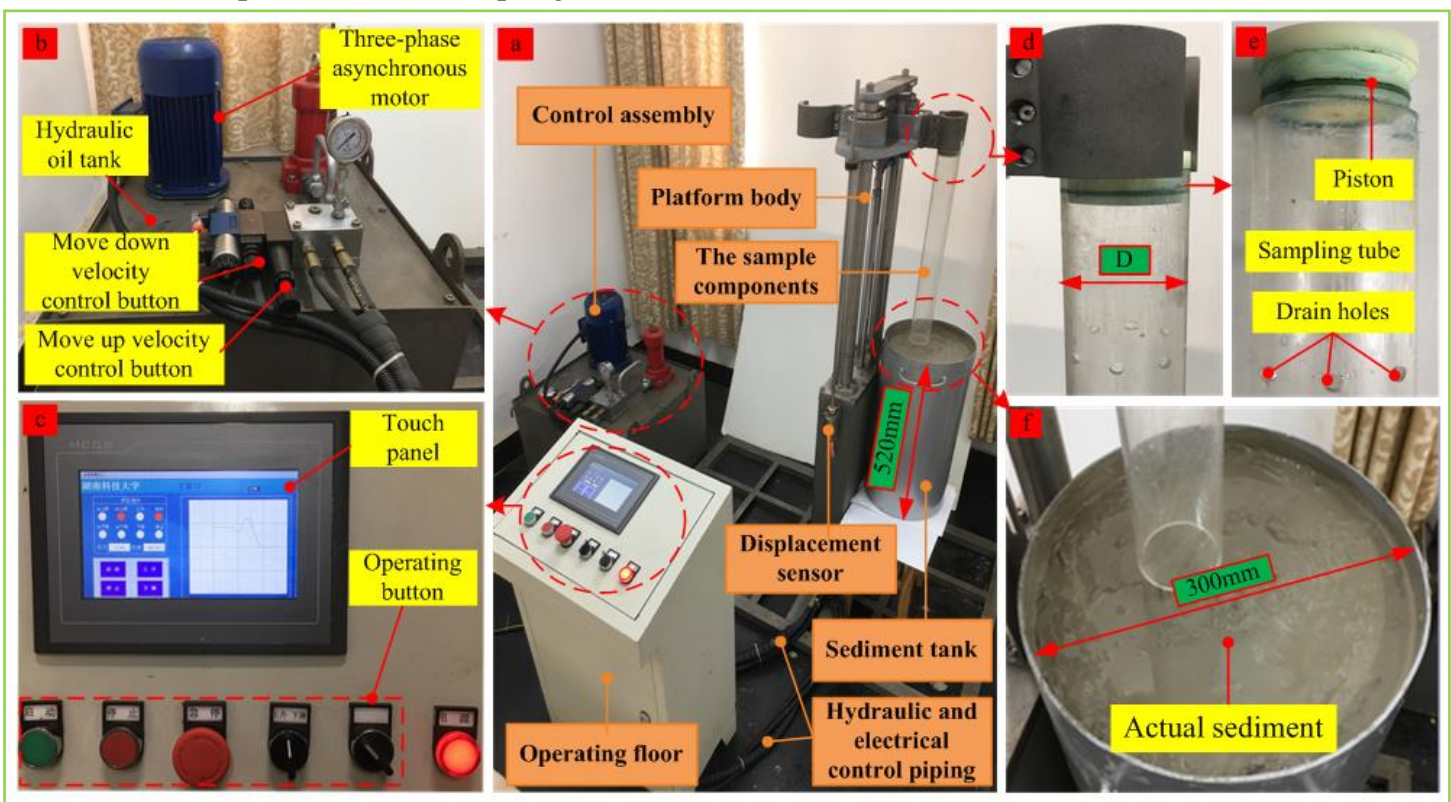

Fig.14 The experimental platform

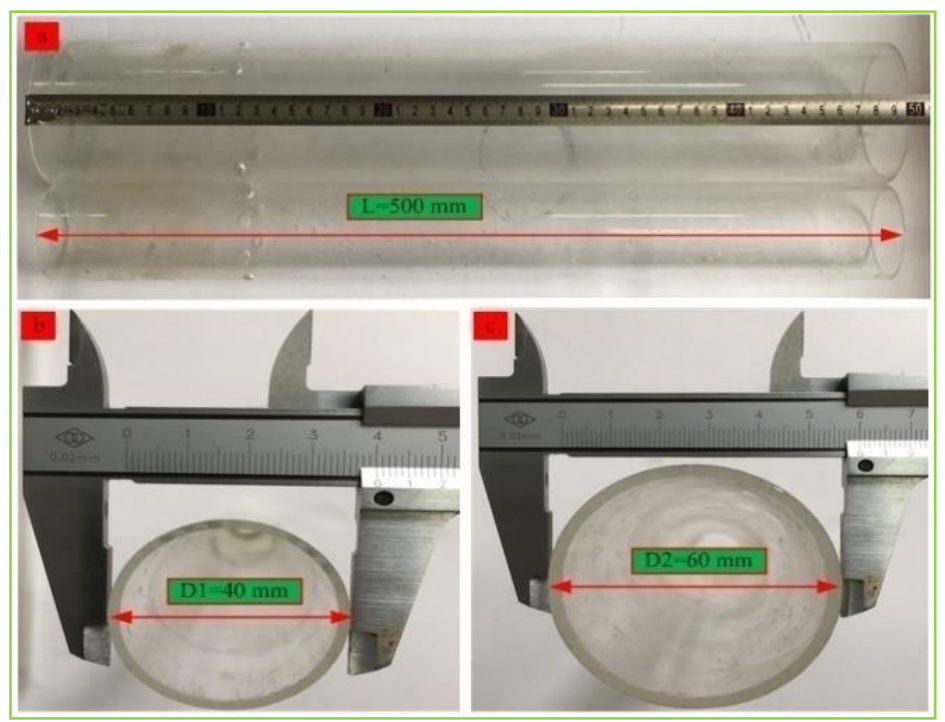

Fig 15 Size of the transparent circular tube

Through simulation analysis, the influences rules of various influencing parameters on the coring volume and rate of the sampler were studied. Based on these simulations and taking the sampler as the experimental object, with a known sediments dynamic viscosity, the actual coring volumes and coring rates under specific conditions were obtained at different velocities of penetration and different tube diameters. The measurement principle for experimental data is shown in Fig. 16. For each velocity, when the sampling tube had been penetrated into the sediments to a depth of $500 \mathrm{~mm}$, the height of the sediments that had entered the sampler was measured, only the height (Ha) from the upper end of the sampling tube to the upper surface of the sediments needed to be measured. During the experiments, when the sampling tube penetrated to the specified depth $(\mathrm{H}=500 \mathrm{~mm})$, as shown in Fig. 17(a), the clamping device was loosened and the top piston was removed as shown in Fig. 17(b, c) at which point the value of Ha was measured, as shown in Fig 17(d). The height of the sediments that had entered the sampling tube was calculated as $\mathrm{Ht}=500-\mathrm{Ha}$, and the experimental data $(\mathrm{Ht})$ were recorded. 


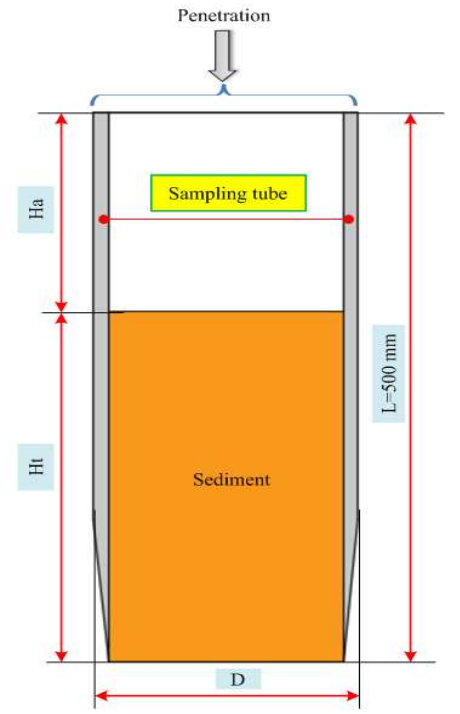

Fig. 16 Measurement principle of experimental data

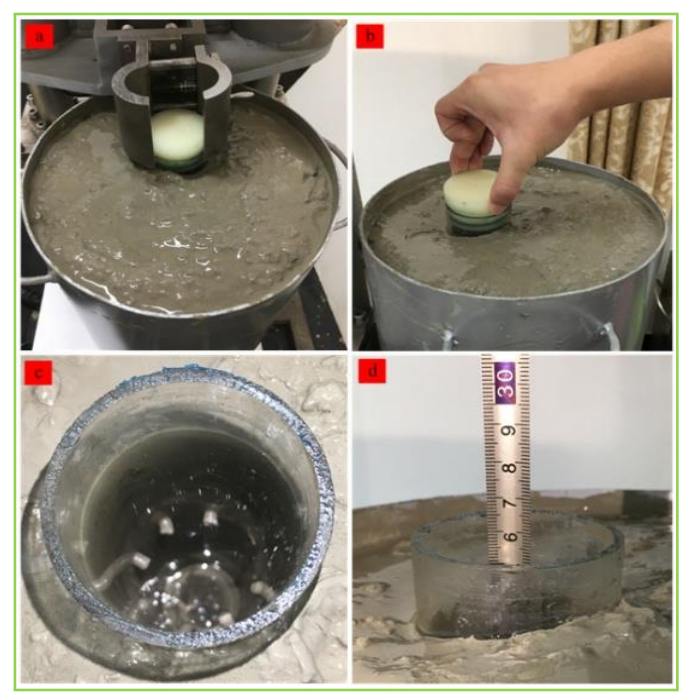

Fig. 17 Experimental measurement procedure

\subsection{Experimental procedures}

The specific operation steps of the experiments were as follows:

(1) First, in order to produce the best model and results, the sediments dynamic viscosity (which was actual sediments taken from the seabed under the "Hainiu" drilling rig) was measured by viscometer. Fig. 18(a) shows the curves of the sediments dynamic viscosity over time at several different temperatures. As can be seen from Fig. 18(b), the sediments dynamic viscosity increased with increases in temperature. The sediments dynamic viscosity tended to stabilize as time progressed. The ambient temperature in the laboratory for the sampling experiments was about $25^{\circ} \mathrm{C}$. According to the curves, after stabilizing, the viscosity value of the experimental sample was about $80 \mathrm{~kg} / \mathrm{m} \cdot \mathrm{s}$.

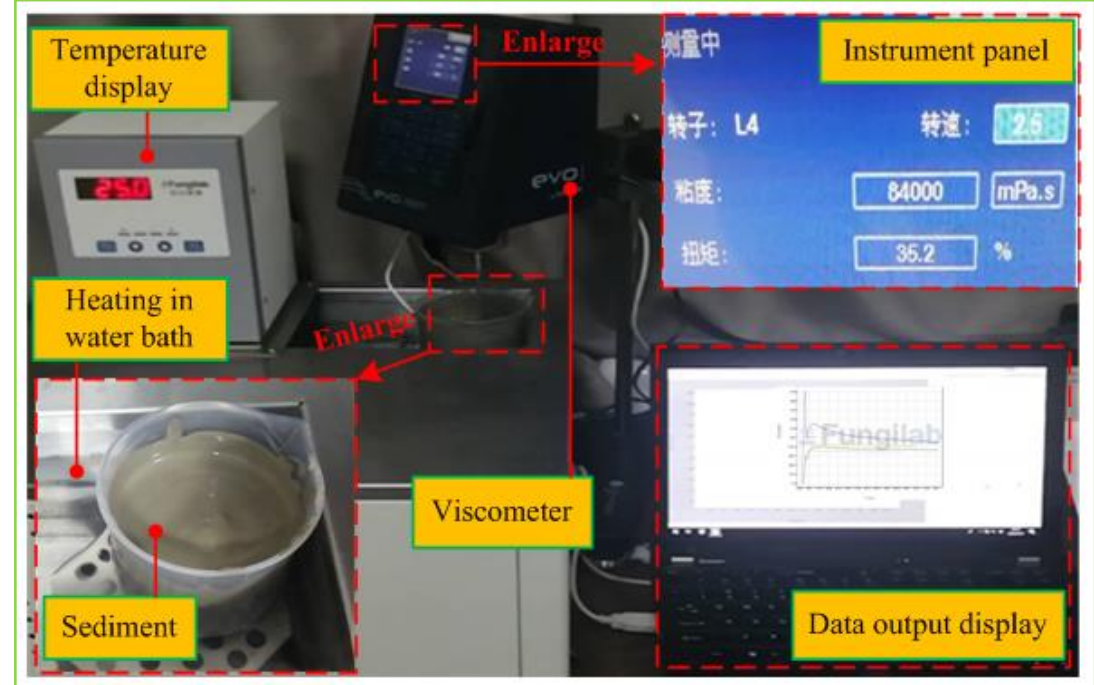

(a) Measurement of experimental data 


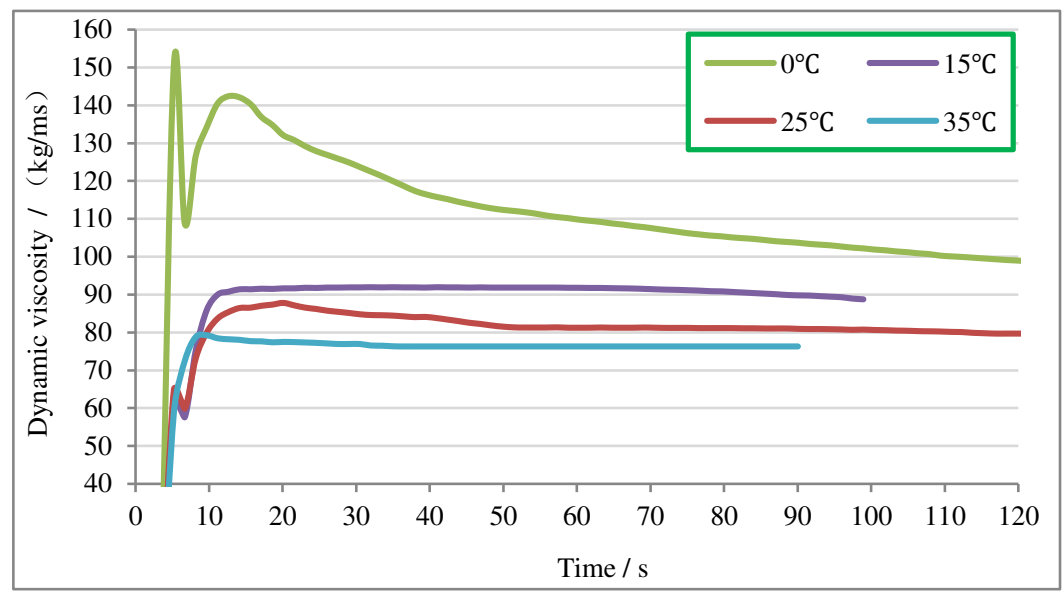

(b) Experimental data

Fig.18 Determination of sediments dynamic viscosity

(2) The actual sediments were transferred to the sediments tank and an appropriate amount of water was added to bring the sediments to a state close to that in the seabed, as shown in Fig. 14(f);

(3) Before starting, the displacement sensor was checked for proper installation, and the data acquisition software was checked to see it was reading correctly;

(4) In order to facilitate sampling observation and collection of experimental data, a transparent circular tube of a given thickness was used for the sampling tube in this experiments. The exact dimensions are shown in Fig. 15. The sampling assembly with an inner diameter (D1) of $40 \mathrm{~mm}$, drain hole diameters (d) of $8 \mathrm{~mm}$, and a length of $500 \mathrm{~mm}$ was installed on the clamping device so that the transparent circular tube was oriented vertically downwards, as shown in Fig. 14(d);

(5) The penetration velocity was adjusted and the sampling experiments were conducted. Penetration velocities of approximately $20 \mathrm{~mm} / \mathrm{s}, 40 \mathrm{~mm} / \mathrm{s}, 50 \mathrm{~mm} / \mathrm{s}$, and $100 \mathrm{~mm} / \mathrm{s}$ were tested. Three experiments were carried out under the same velocity and the average value was recorded.

(6) The sampling tube with an inner diameter (D2) of $60 \mathrm{~mm}$, drain hole diameters of $12 \mathrm{~mm}$, and a length of $500 \mathrm{~mm}$ was then installed on the clamping device so that the sampling tube was oriented vertically downward;

(7) The operations in step (5) were repeated for the second sampling tube.

\subsection{Experimental results}

Using sampling tube diameters of $40 \mathrm{~mm}$ and $60 \mathrm{~mm}$, sampling experiments were carried out at different velocities. The height of the sediments in the sampling tube Ht can be obtained, and then the corresponding coring volumes and rates were calculated. The experimental results are shown in Table 2, where: Ht represents the experimental value of sediments height in the sampling tube; Hs represents the simulated calculation value of sediments height in the sampling tube; and the last row provides the absolute error between the experimental results and the computational results.

\begin{tabular}{ccccc||cccc}
\multicolumn{10}{c||}{ Table 2 Experimental results } \\
\hline Number & 1 & 2 & 3 & 4 & 5 & 6 & 7 & 8 \\
\hline $\mathrm{D} /(\mathrm{mm})$ & \multicolumn{1}{c|}{40} & & & 60 \\
\hline $\mathrm{v} /(\mathrm{mm} / \mathrm{s})$ & 20 & 40 & 50 & 100 & 20 & 40 & 50 & 100 \\
\hline$H_{\mathrm{s}} /(\mathrm{mm})$ & 198 & 150 & 136 & 118 & 240 & 190 & 180 & 152 \\
\hline$H_{\mathrm{t}} /(\mathrm{mm})$ & 192 & 155 & 140 & 113 & 230 & 196 & 172 & 145 \\
\hline $\mathrm{e}=\frac{\left|H_{\mathrm{t}}-H_{\mathrm{s}}\right|}{H_{\mathrm{s}}} \times 100 \%$ & $3.0 \%$ & $3.3 \%$ & $2.9 \%$ & $4.2 \%$ & $4.2 \%$ & $3.2 \%$ & $4.4 \%$ & $4.6 \%$ \\
\hline
\end{tabular}

In order to compare the experimental results with the simulated results more clearly, curves were constructed (Fig. 19): the blue curves are the simulation computational results and the red curves are the experimental results; (a) and (c) show the relationships between coring volume and the penetration velocity for D1 $(40 \mathrm{~mm})$ and D2 $(60 \mathrm{~mm})$ sampling tubes, respectively; and (b) and (d) show the relationships between coring rate and the penetration velocity for D1 and D2, respectively. 


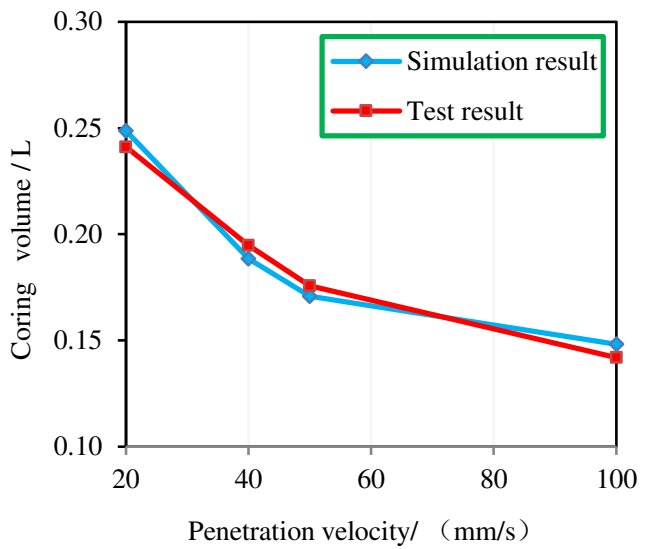

(a)

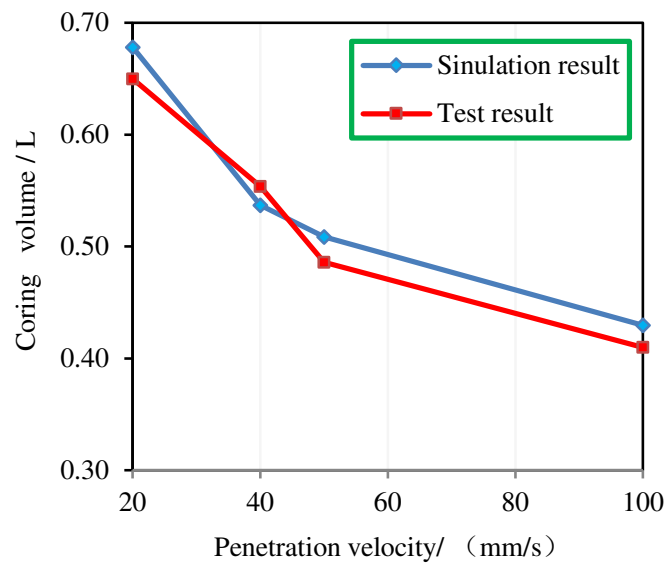

(c)

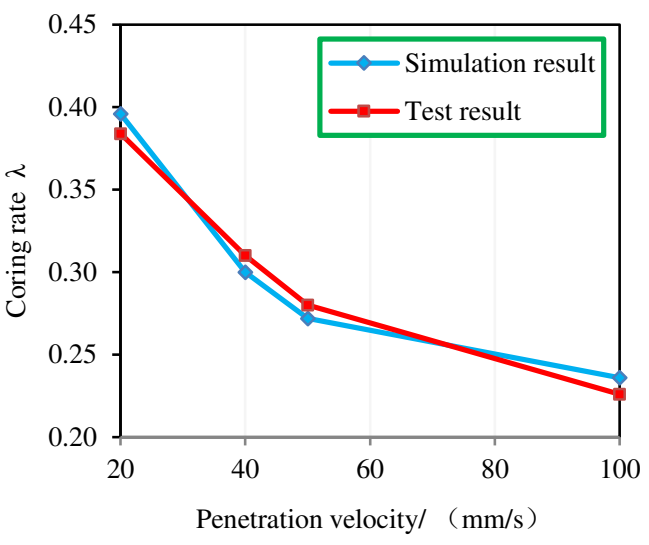

(b)

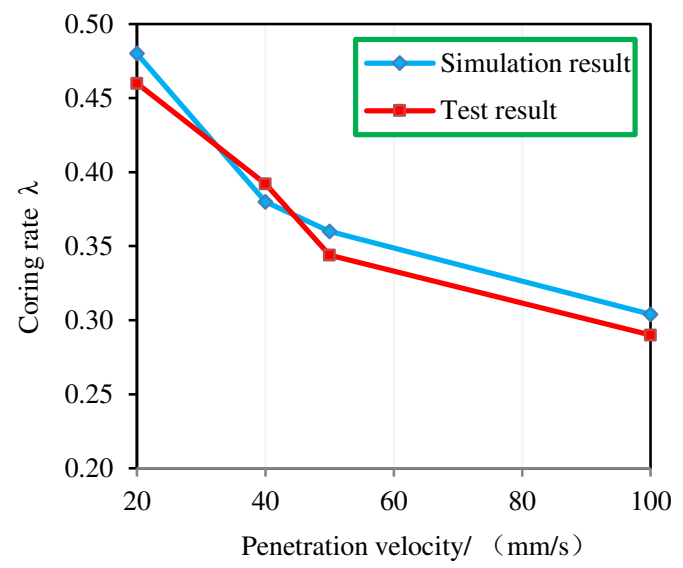

(d)

Fig 19 Comparison of simulation and experimental results

From the comparison of the results, it appeared that the simulated results satisfactorily matched the experimental results as the maximum absolute error was only $4.6 \%$. This shows that the sediments sampling model established in this paper was reliable and produced results that accurately reflected real-world observations.

Due to the limitations of the experimental equipment, there was no way to accurately control the penetration velocity. Similarly, the sediments dynamic viscosity may have also changed with changes in the sediments water content and laboratory ambient temperature. Also, due to the difficulty in obtaining deep-sea sediments, the simulated sediments from which experimental sediments cores were extracted was small and may not accurately reflect natural sediments substrates, which are deep and unconstrained. These limitations will inevitably produce some degree of error between the computational results and the experimental results.

\section{Conclusions}

In this paper, the sediments on the seabed were simulated as a non-Newtonian Herschel-Bulkley viscoplastic fluid. A numerical model for sediments sampling was established and the influence rules of various key parameters on the coring rates and the volumes were particularly studied. The findings in this paper can provide a theoretical basis for facilitating the optimal design of the geometric structure of the seabed sediments samplers and the parameters in the sampling process. The following conclusions were obtained:

(1) Coring volume increased with increases in the sampling tube diameter, but decreased with increased penetration velocity, drainage area rate, and sediments dynamic viscosity. Coring rate decreased with increased penetration velocity, drainage area rate, and sediments dynamic viscosity. The coring rate first increased and then decreased with increasing sampling tube diameter, and the peak value was also related to the penetration velocity.

(2) When the drainage area rate was less than or equal to 3 , the coring volume and coring rate remained basically unchanged; but when the drainage area rate was greater than 3 , the coring volume and coring rate decreased with increasing drainage area rate. The larger the sampling tube diameter, 
the more pronounced this decreasing trend was. These relationships provide important guidelines for the design of drainage discharge ports in similar samplers.

(3) A sampling experimental platform was set up to conduct physical experiments. The simulation results tallied with the experimental results, with a maximum absolute error of only $4.6 \%$, which verified that the numerical simulation model accurately reflected real-world sampling.

\section{Declaration}

\section{Acknowledgements}

The author sincerely thanks to Professor Deshun Liu of Hunan University of Science and technology for his critical discussion and reading during manuscript preparation.

\section{Funding}

Supported by National Key R\&D Program of China (Grant no. 2016YFC0300502), and the National Natural Science Foundation of China (Grant no.51705145, 517779092). This work is also supported by Scientific Research Fund of Hunan Provincial Education Department (Grant no.18B205) and Hunan Province Natural Science Foundation (Grant no.2019 JJ50182).

\section{Availability of data and materials}

The datasets supporting the conclusions of this article are included within the article.

\section{Authors' contributions}

The author' contributions are as follows: Youduo Peng was in charge of the whole manuscript; Shudong He wrote the manuscript; Jian Yan and Yongping Jin assisted in data collection. Buyan Wan provided ideas on manuscript writing.

\section{Competing interests}

The authors declare no competing financial interests.

\section{Consent for publication}

Not applicable

\section{Ethics approval and consent to participate}

Not applicable

\section{Reference}

[1] RAHUL S. Deep sea mining economic, technical, technological, and ambient considerations for sustainable development. Marine Technology Society Journal. 2017, 5(5): 28-41.

[2] Sharma R. Deep-Sea mining: Economic, Technical, Technological, and Environmental Considerations for Sustainable Development. Mar.technol.soc.j.2011, 45(45):28-41.

[3] JIN S C. Deep ocean mining technology III developments. Proceedings of the Eighth International Society of Offshore and Polar Engineers Ocean mining Symposium, September20-24, 2009, Chennai, India, 2009: 1-7.

[4]Mogg, A. O. M., Attard, K. M., et al. The influence of coring method on the preservation of sedimentary and biogeochemical features when sampling soft-bottom, shallow coastal environments. Limnology and Oceanography: Methods. 2017,15(11):905-915.

[5]Dueck, Y.,Lorke, A., et al. Laboratory and field investigations on freeze and gravity core sampling and assessment of coring disturbances with implications on gas bubble characterization. Limnolgy and Oceanography Methods. 2019,17 (11): 585-606.

[6] Rongve D.,Arne H. E. Shortening of surface sediment cores during sampling. Hydrobiologia, 1979, 65(3):283-287.

[7]Jensen, P. Meiofauna abundance and vertical zonationin a sublittoral soft bottom, with a test of the haps corer. Mar. Biol. 1983,74: 319-326.

[8]Leonard, R. An assessment of sediment loss and distortion at the top of short gravity cores. Sediment Geol.1990, 66:57-63.

[9]Emery, K.O., Dietz, R.S. Gravity coring instrument and mechanics of sediment coring. Bull. Geol. Soc. Am. 1941, 52:1685-1714. 
[10] Carter, J .P, Randolph, M.F.,et al. Stress and pore pressure changes in clay during and after expansion of a cylindrical carity.lnt. J.Numer. Analyst. Mech. Geomech. 1979,3 (3).

[11] Brank L, Adolfo F. A numerical solution of cavity expansion problem in sand based directly on experimental stress-strain curves. Canadian Geotechnical Journal. 1998,35(4).

[12]Tatsvnovi,et al.. Effects of plug on behavior of driven pipe piles. Soil and Foundation. 1991,31 (2).

[13] Skinner, L. C., I. N. McCave. Analysis and modelling of gravity- and piston coring based on soil mechanics. Mar. Geol. 2003.199: 181-204.

[14] Chopra, M. B., et al. Finite-element analysis of time-dependent large deformation problems. Int. for Numer. Analyst. Mesh. Geomech, 1992,16.

[15] Randolph M F. et al. One-dimensional analysis of soil plugs in pipe piles. Geotechnique. 1991,41

(2).

[16]Wen Zhou, Hua-wei Qin, Chen Ying. Finite element analysis of sediment sampling disturbance in the seabed. Marine science. 2009,33(12).

[17] Qin, H., Cai, Z., Hu, H., Wang, J., Ye, W., \& Chen, Y. Numerical Analysis of Gravity Coring Using Coupled Eulerian-Lagrangian Method and a New Corer. Marine Georesources\& Geotechnology, 2014,34(5): 403-408.

[18] Guo, Y., Yu, X. (Bill). Soil Plugging Mechanism on Large Diameter Pipe Piles: Insight from Discrete Element Simulations. IFCEE 2015. 


\section{Figures}

High-pressure valve Gas-tight coupler Piston Drain holes Sampling tube Sediment catchers

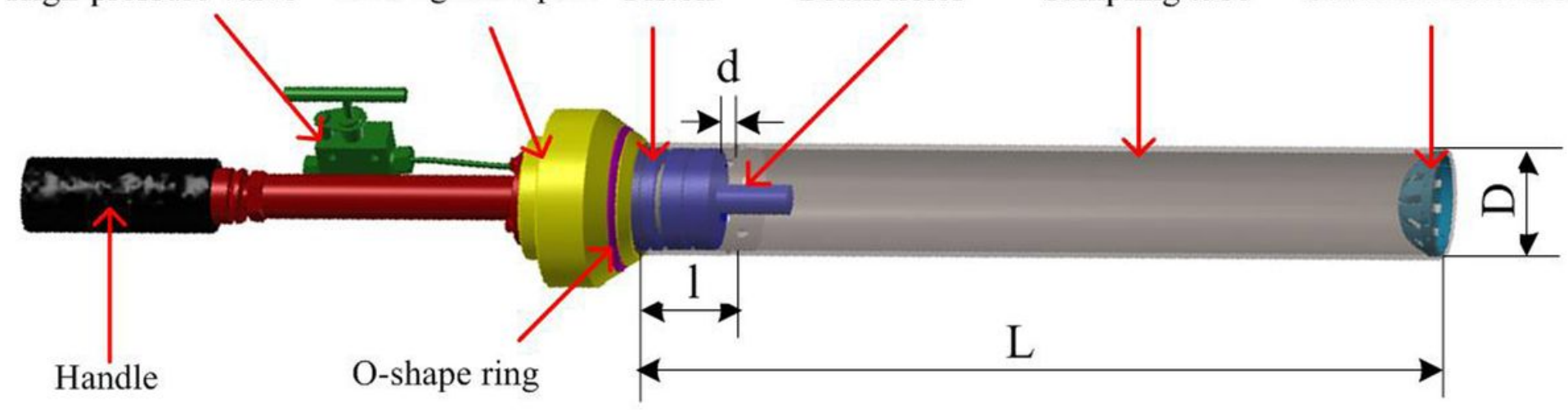

Figure 1

Structure of the sampling device

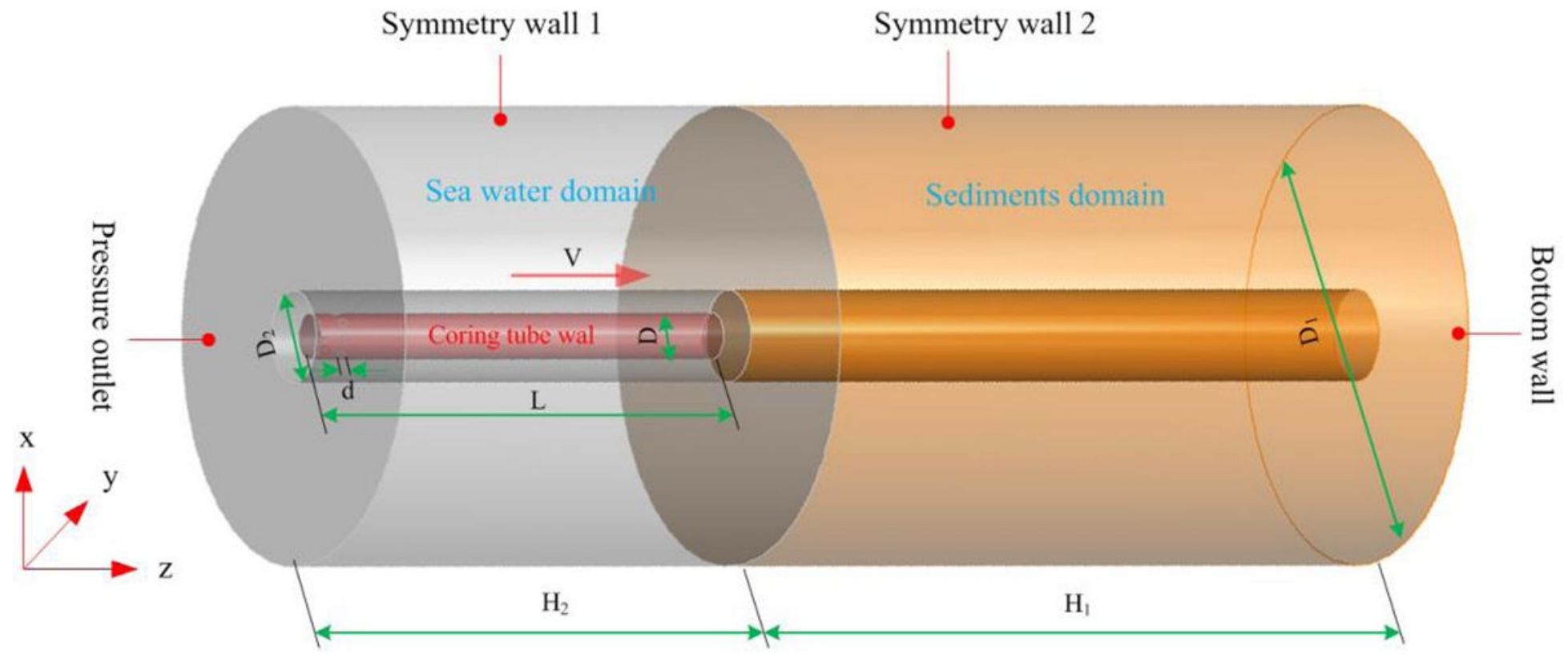

Figure 2

3D computational fluid dynamics model of sampling 


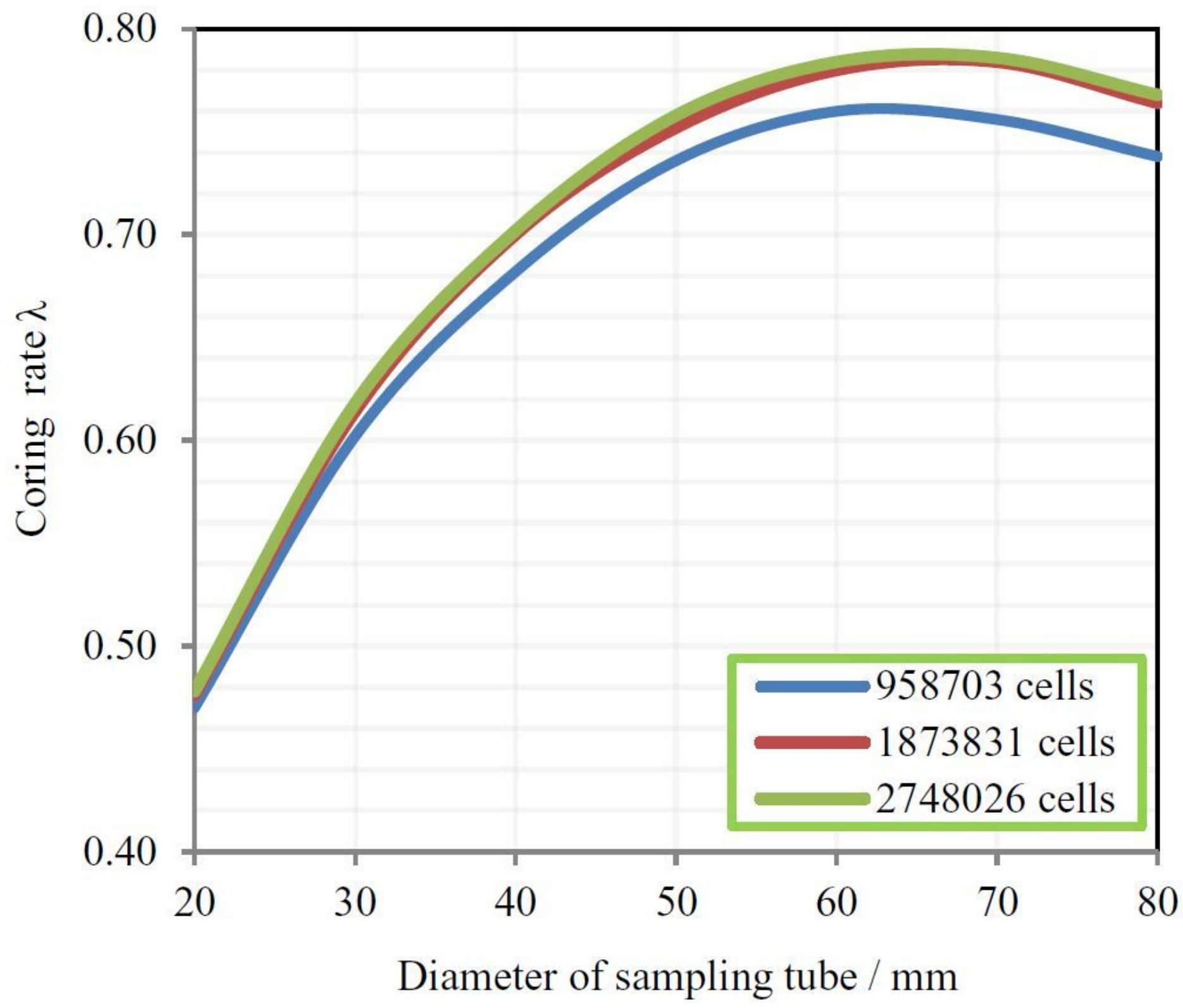

Figure 3

Coring rates under different grid models 


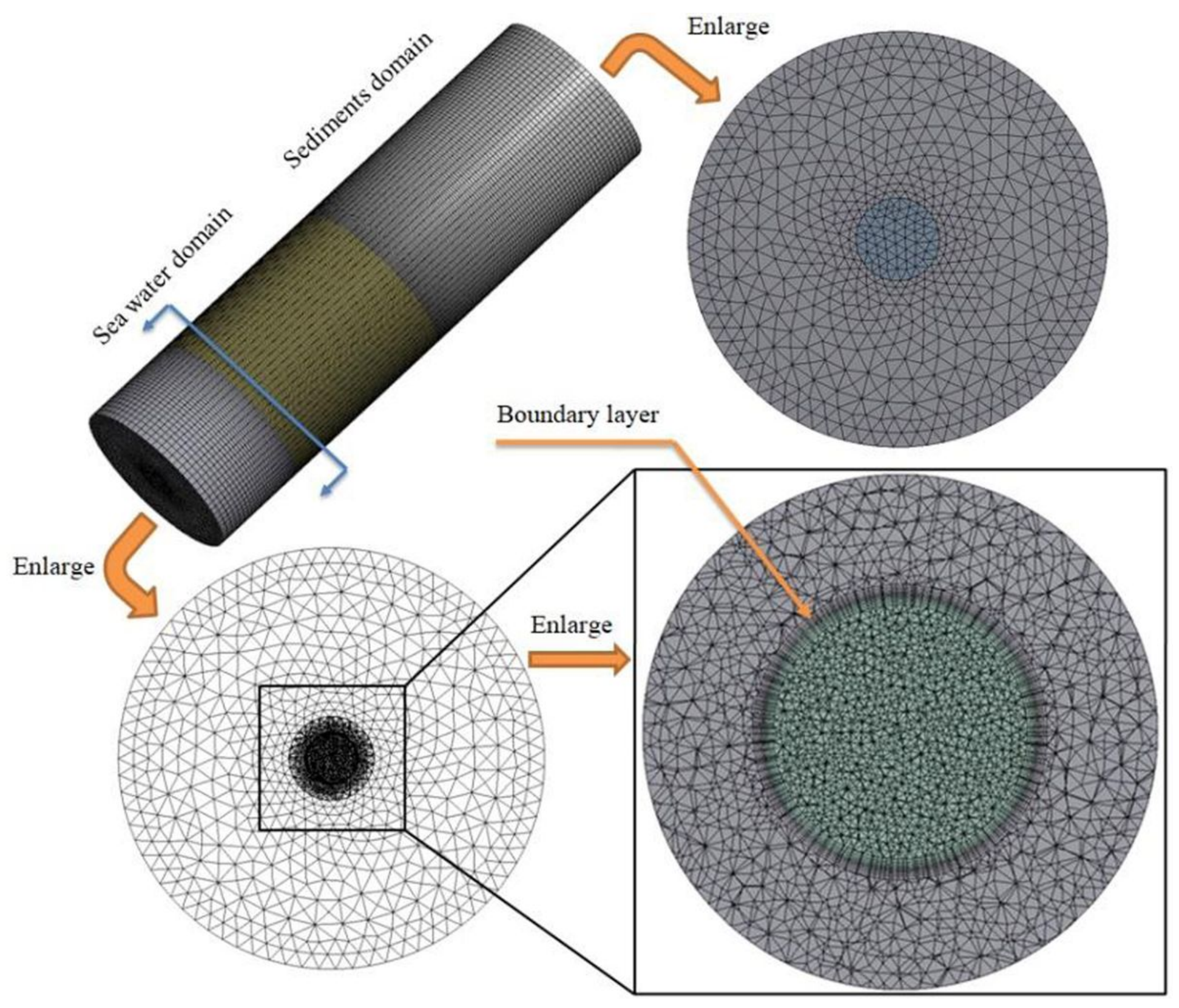

Figure 4

Three grid models of sampling 
Phase 1.Volume Fraction Contour 1

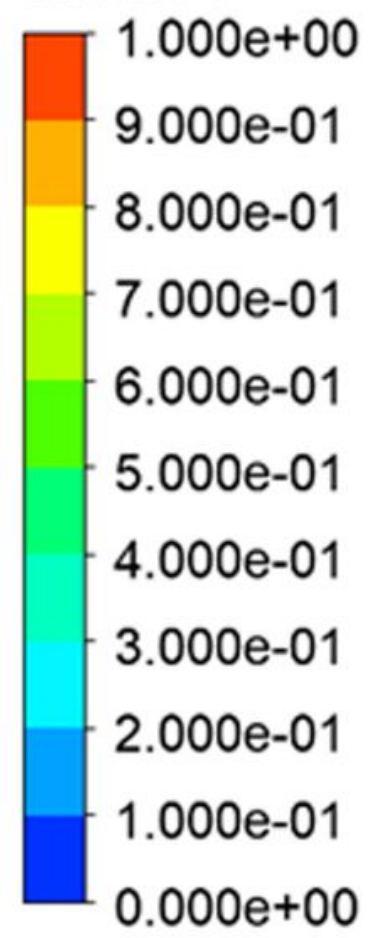

Z

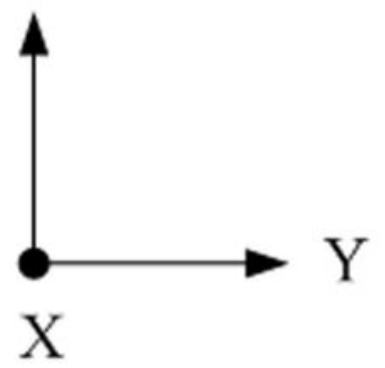

Figure 5

Sketch map of sampling

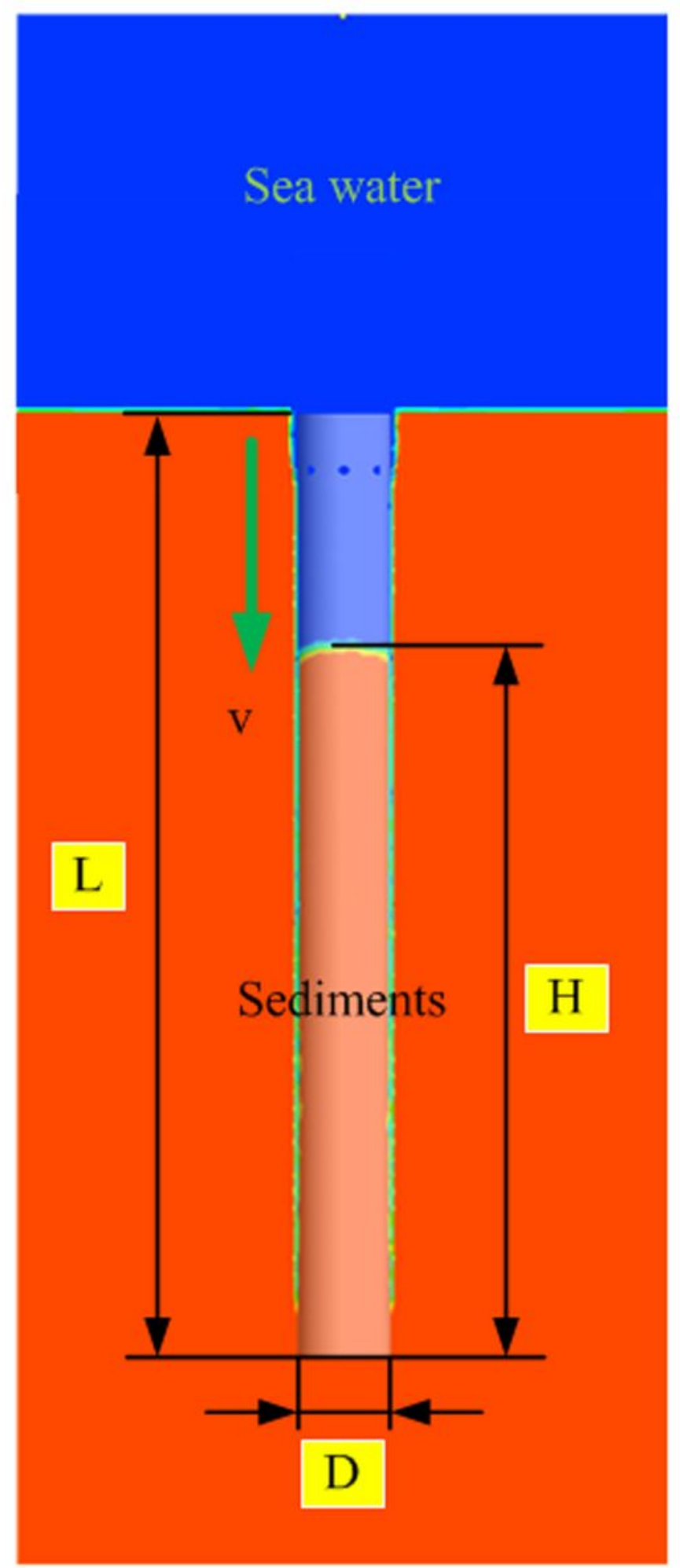




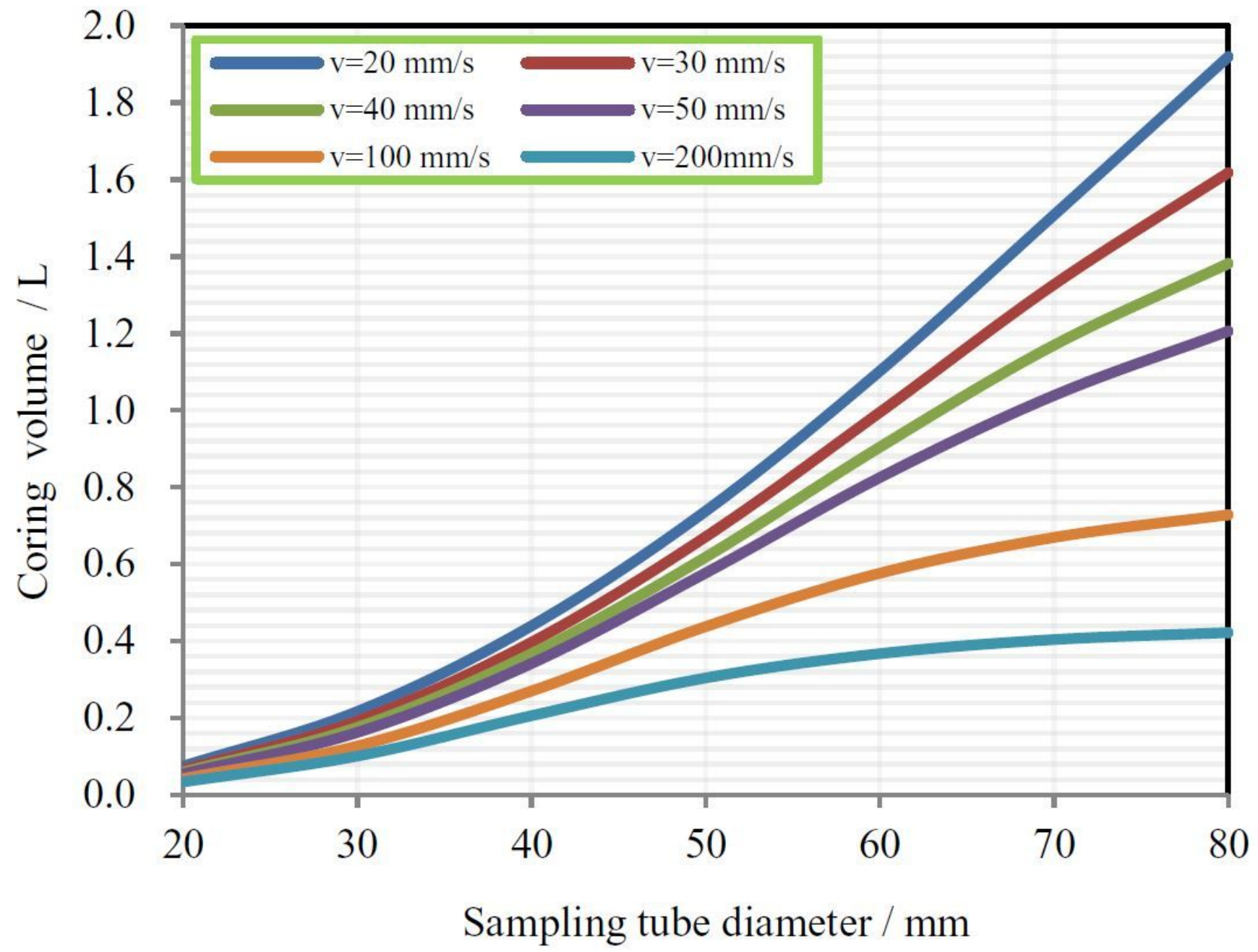

Figure 6

The influence curve of the sampling tube diameter on the coring volume 


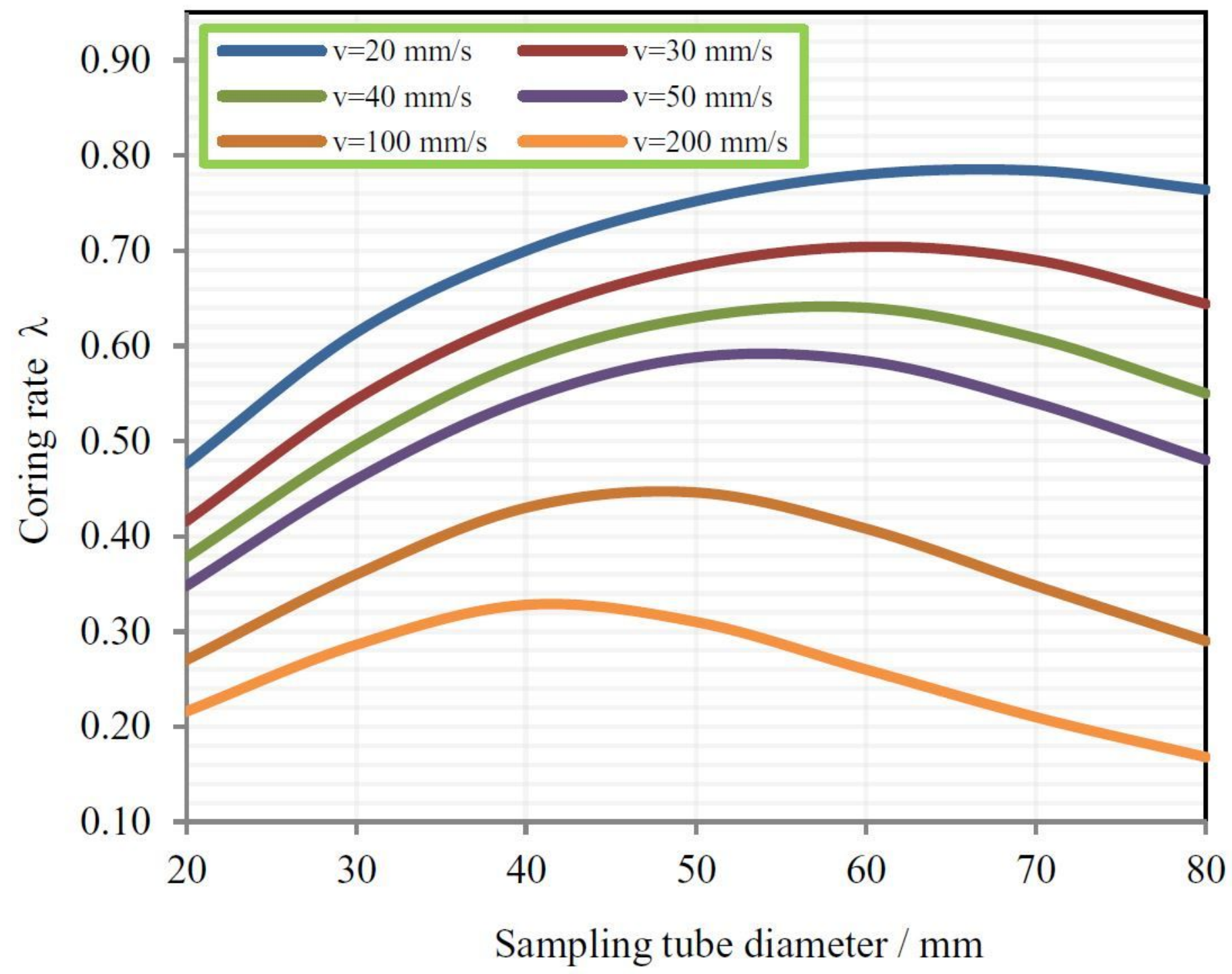

Figure 7

The influence curve of the sampling tube diameter on the coring rate 


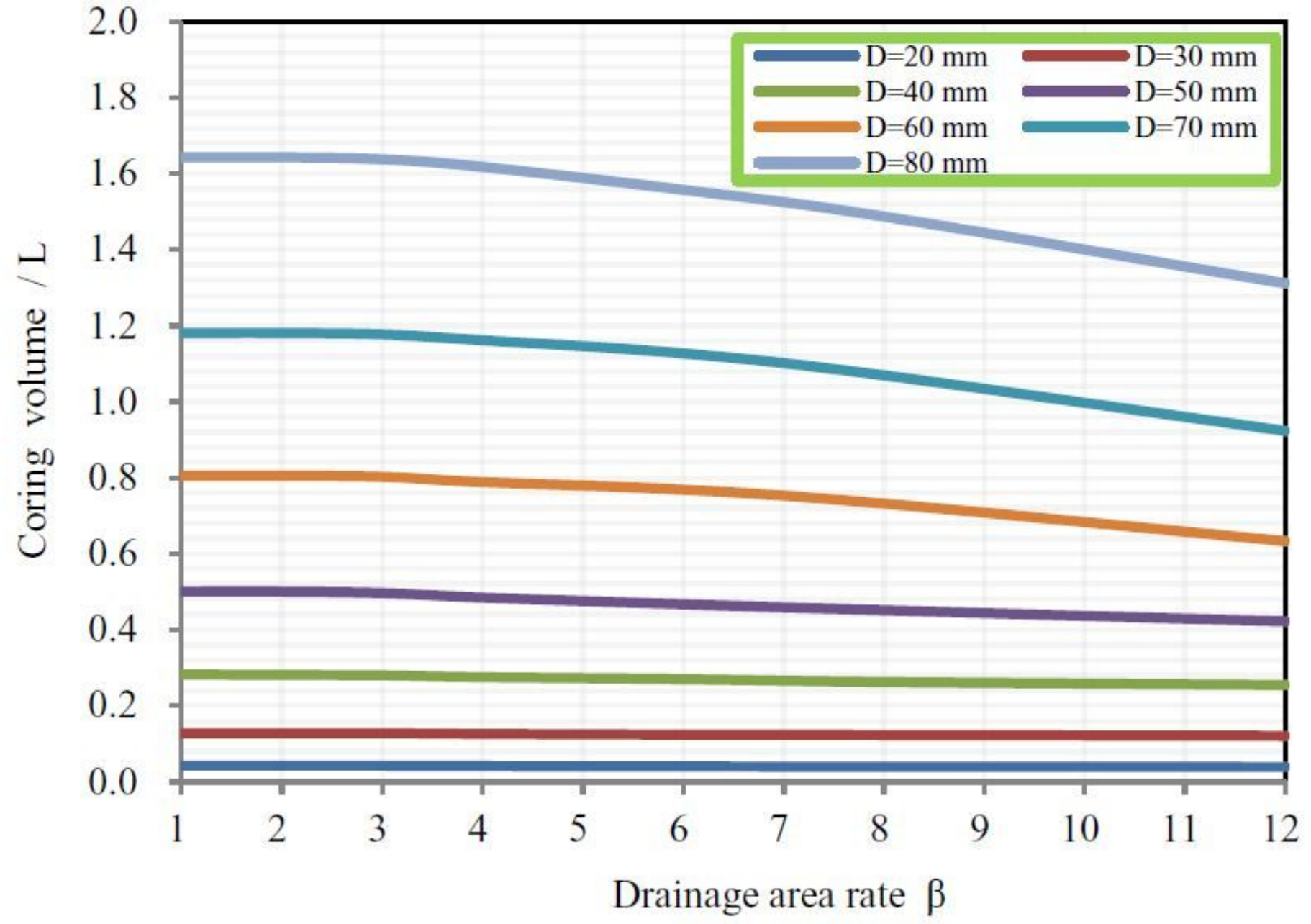

Figure 8

The influence curve of the drainage area rate on the coring volume 


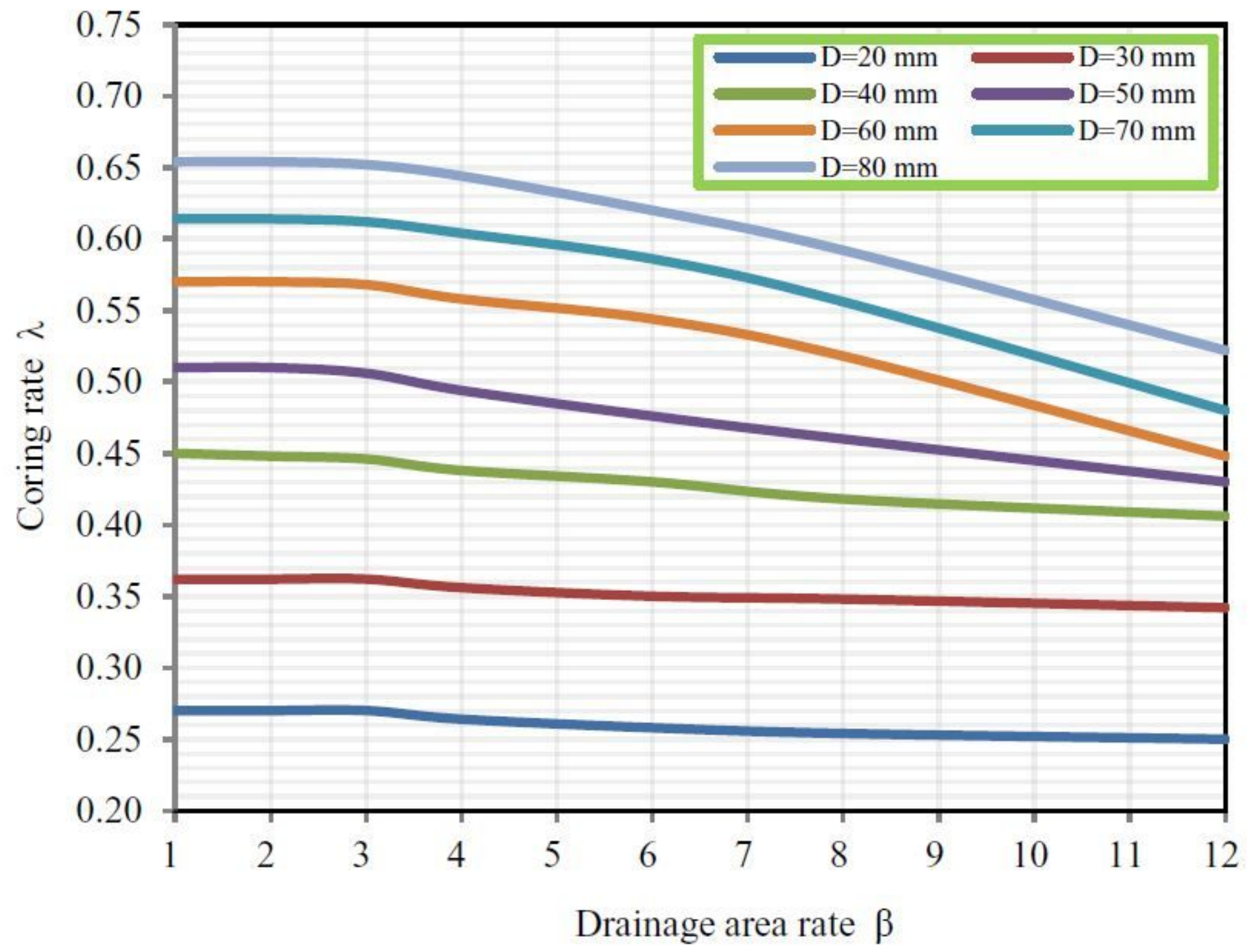

Figure 9

The influence curve of the drainage area rate on the coring rate 


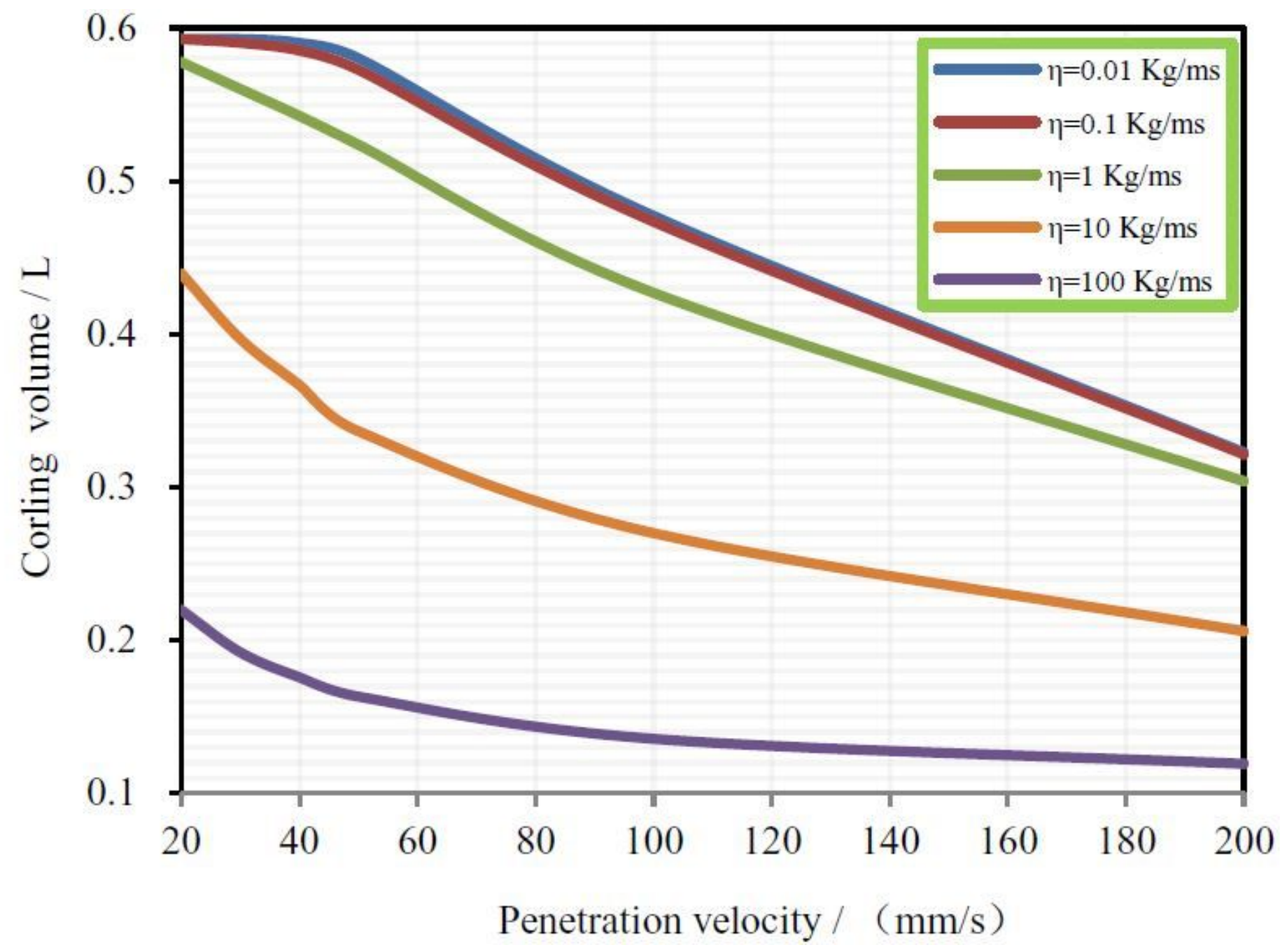

Figure 10

The influence curve of the penetration velocity on the coring volume 


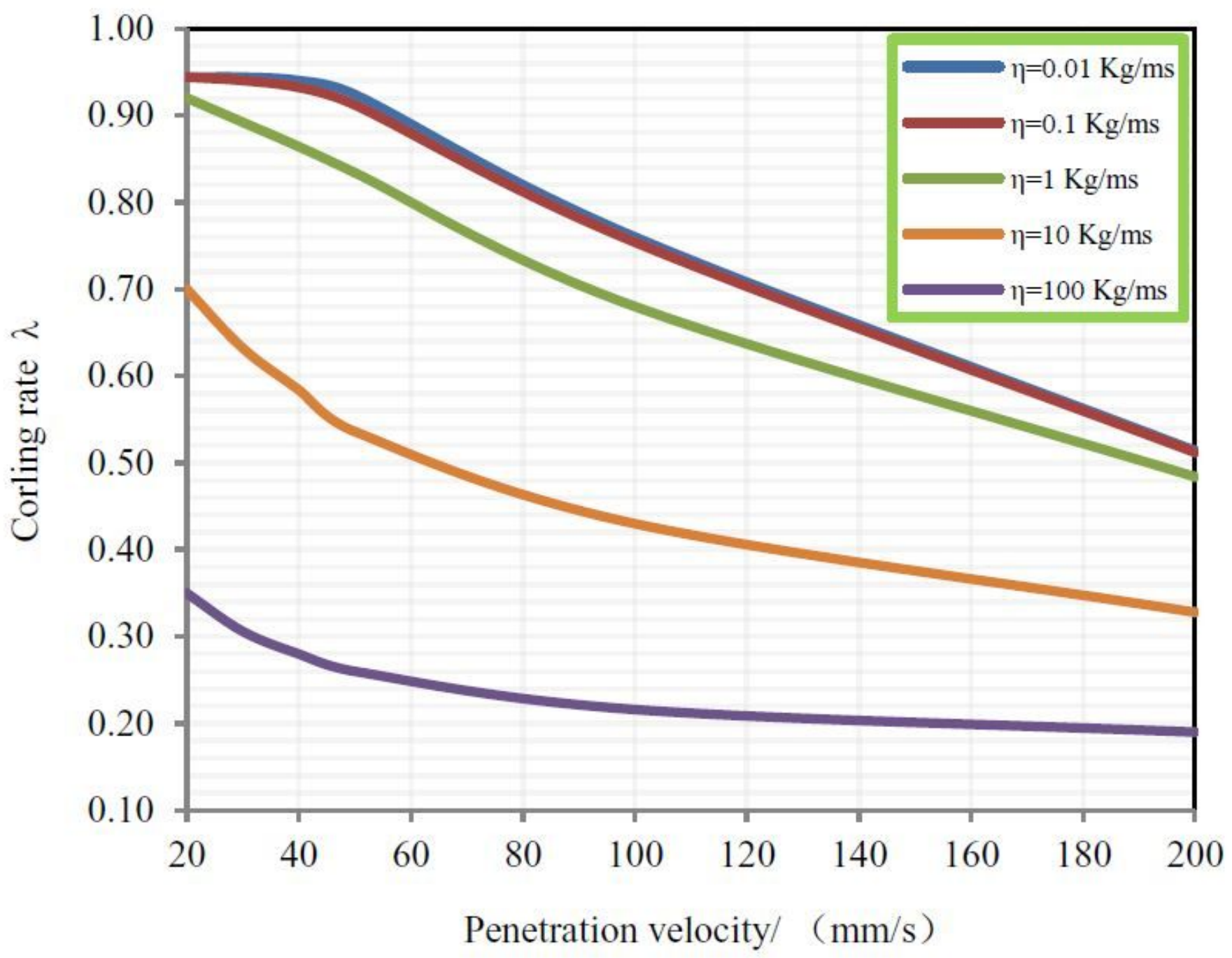

Figure 11

The influence curve of the penetration velocity on the coring rate 


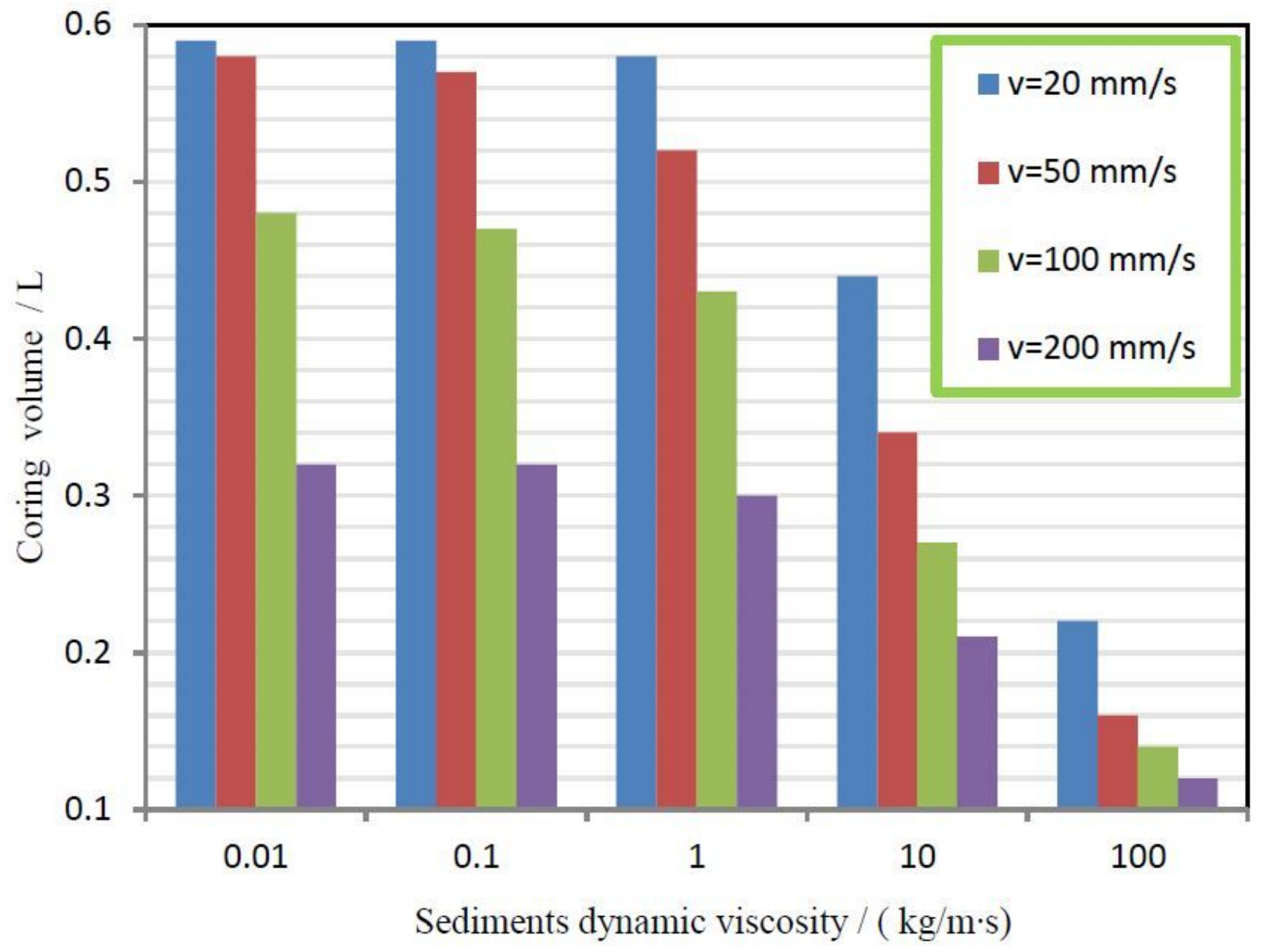

Figure 12

The influence curve of the sediments dynamic viscosity on the coring volume 


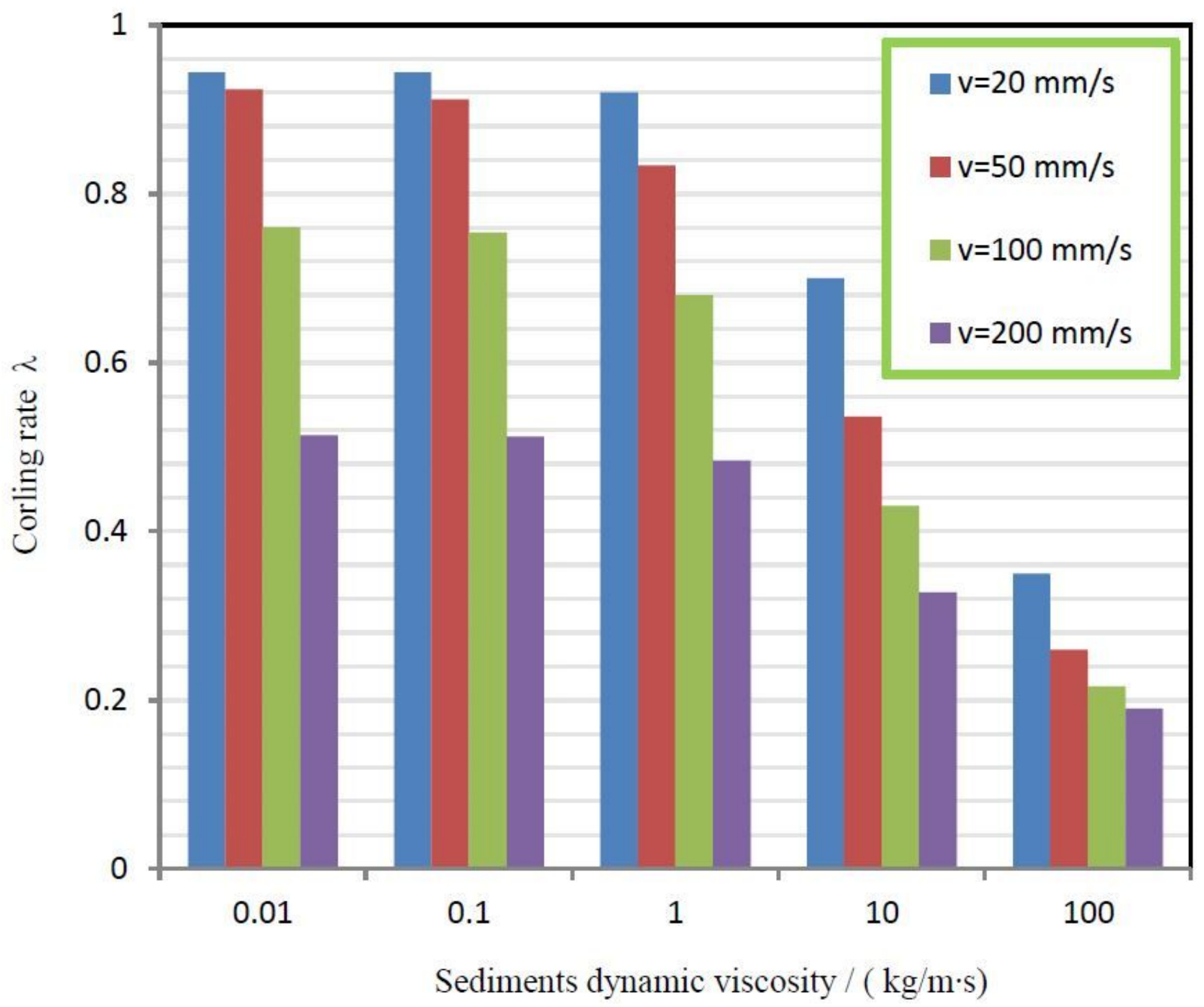

Figure 13

The influence curve of the sediments dynamic viscosity on the coring rate 

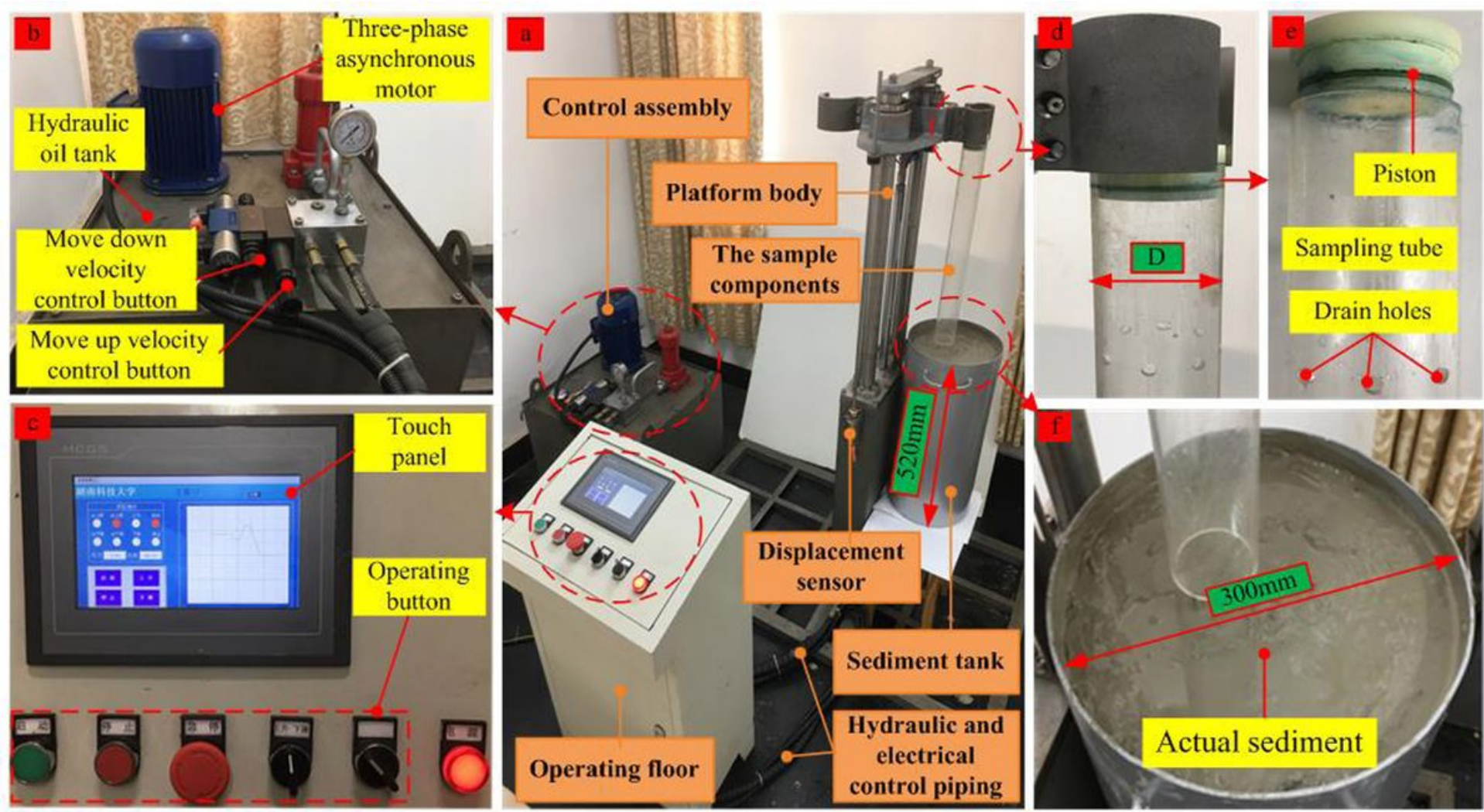

Figure 14

The experimental platform 


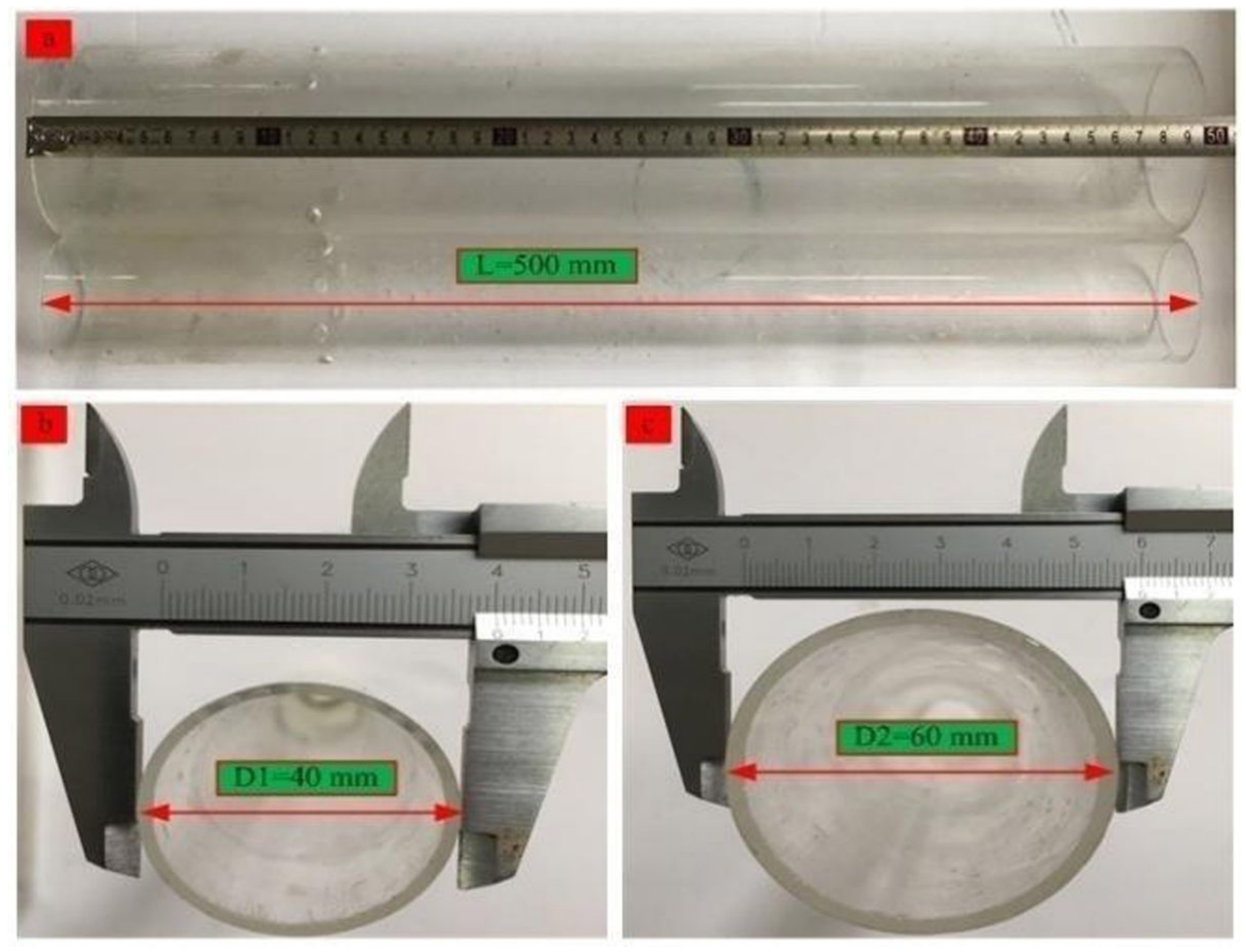

Figure 15

Size of the transparent circular tube 


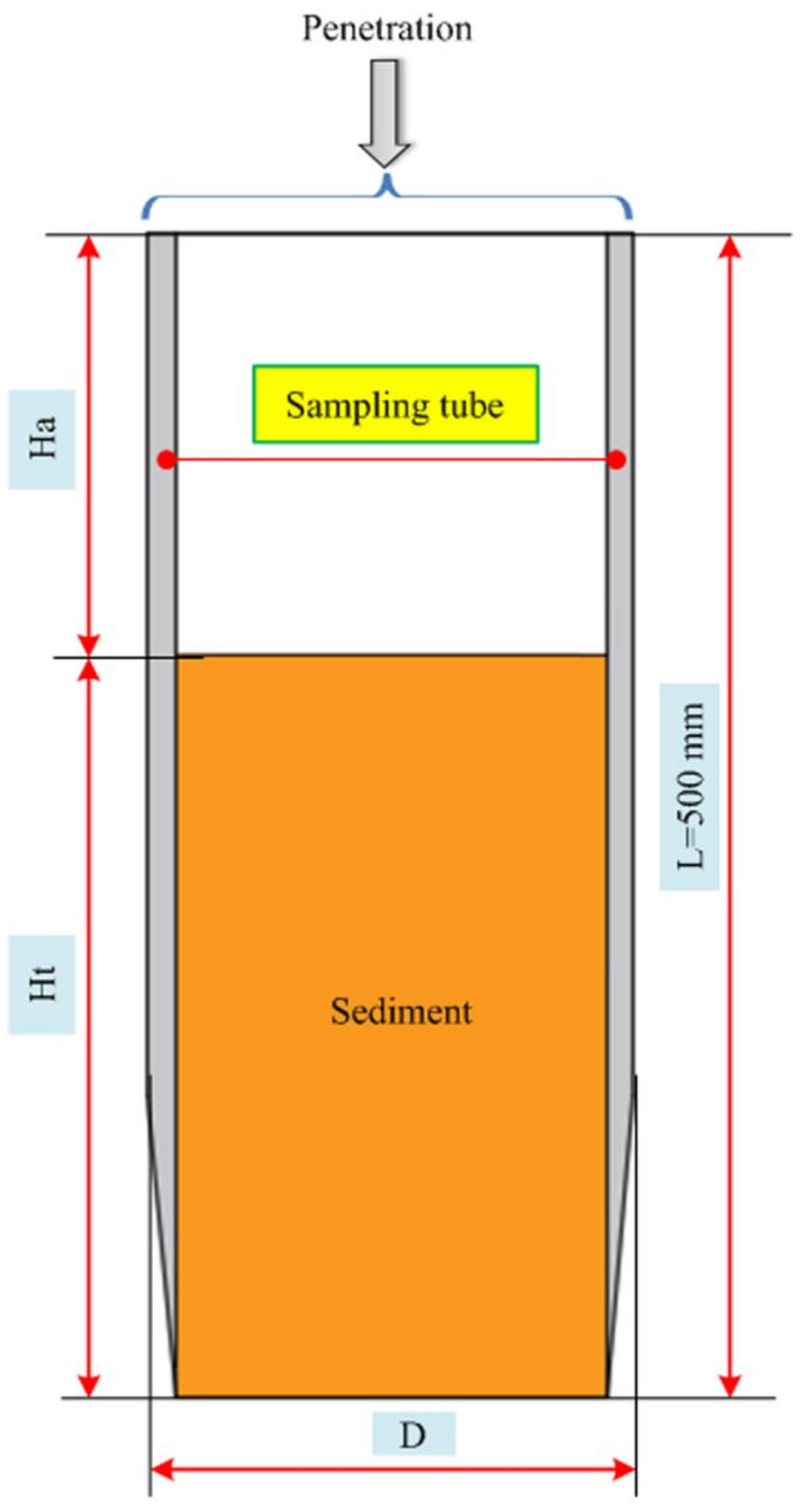

Figure 16

Measurement principle of experimental data 

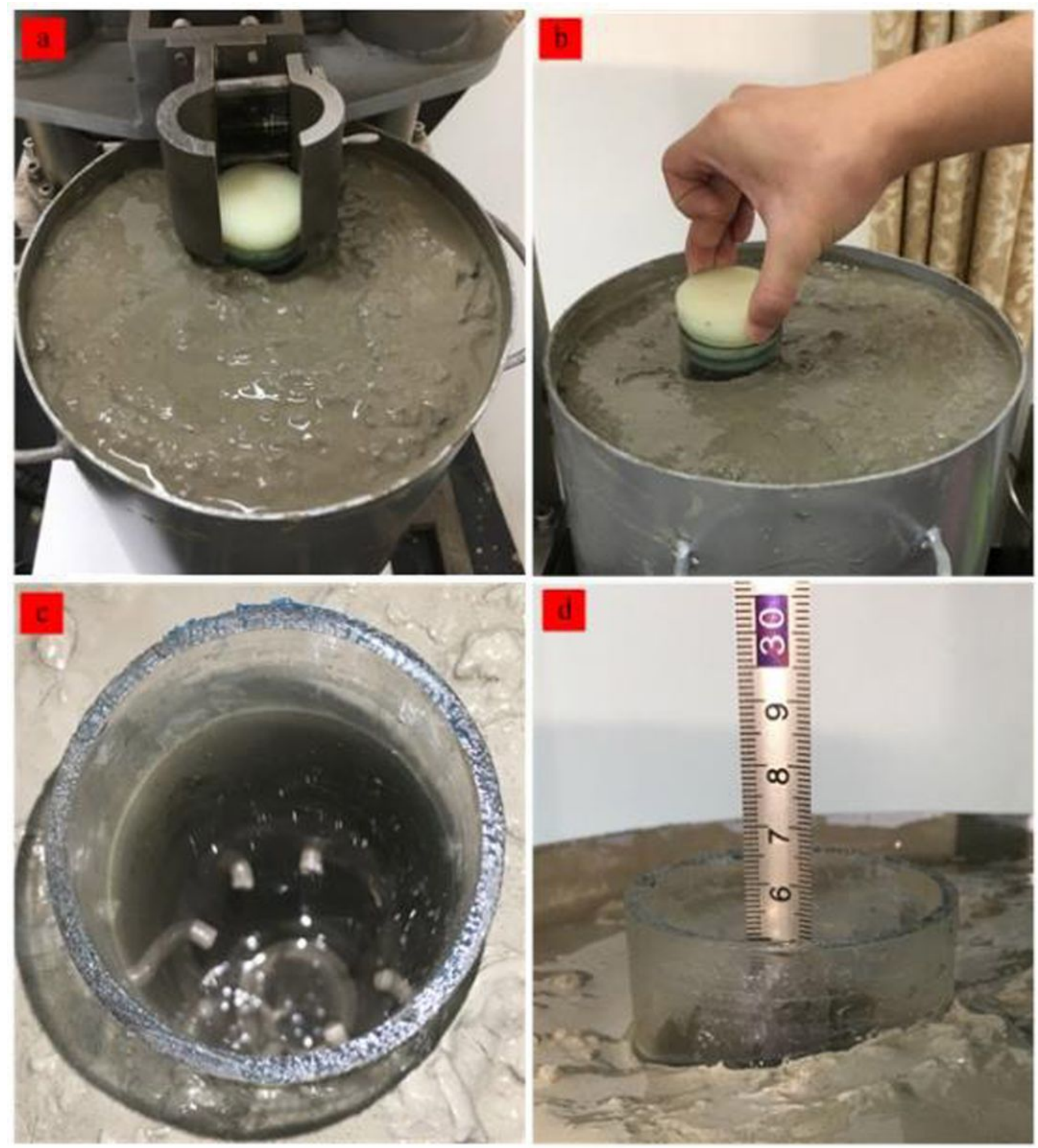

Figure 17

Experimental measurement procedure 


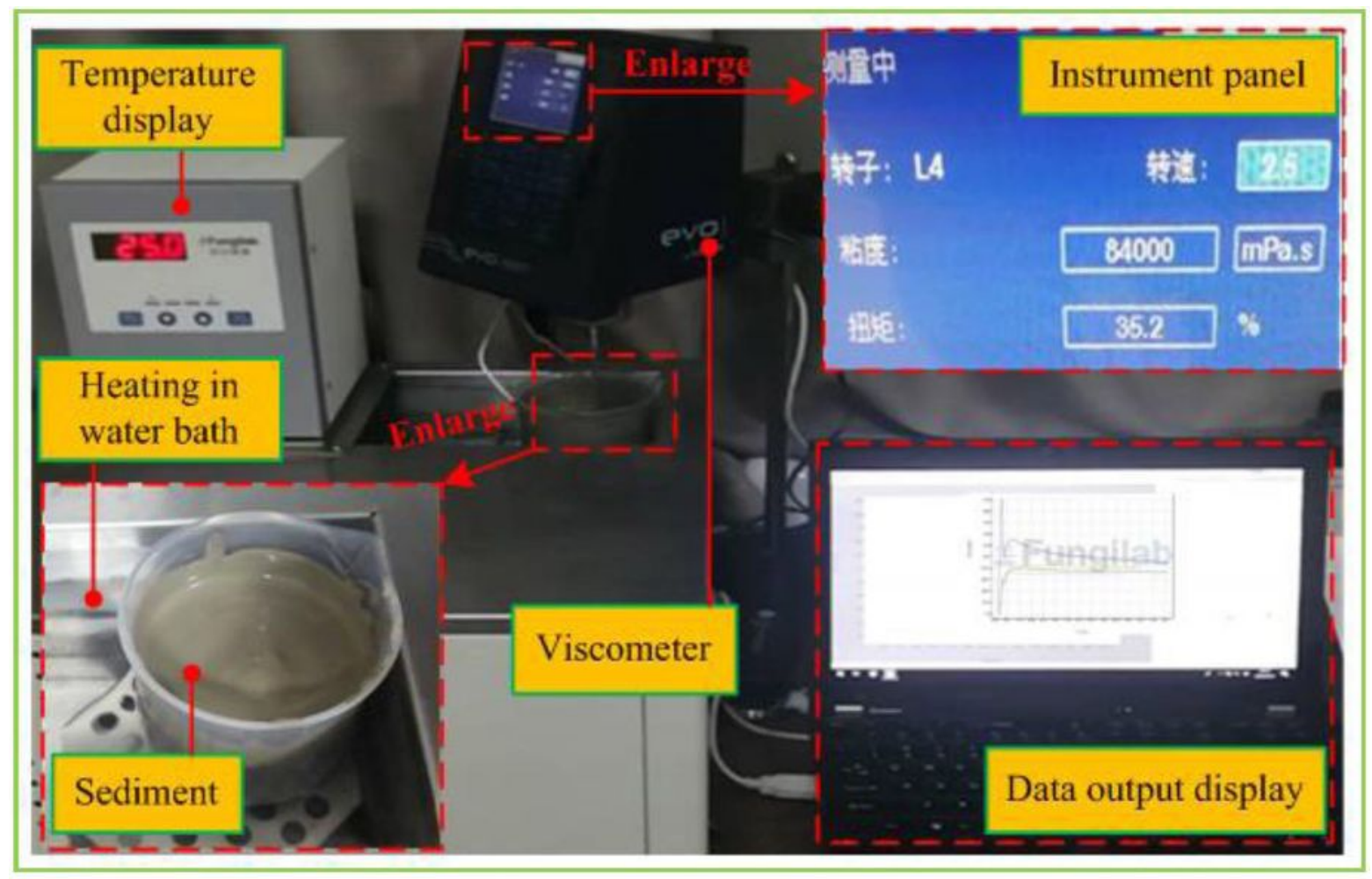

(a) Measurement of experimental data

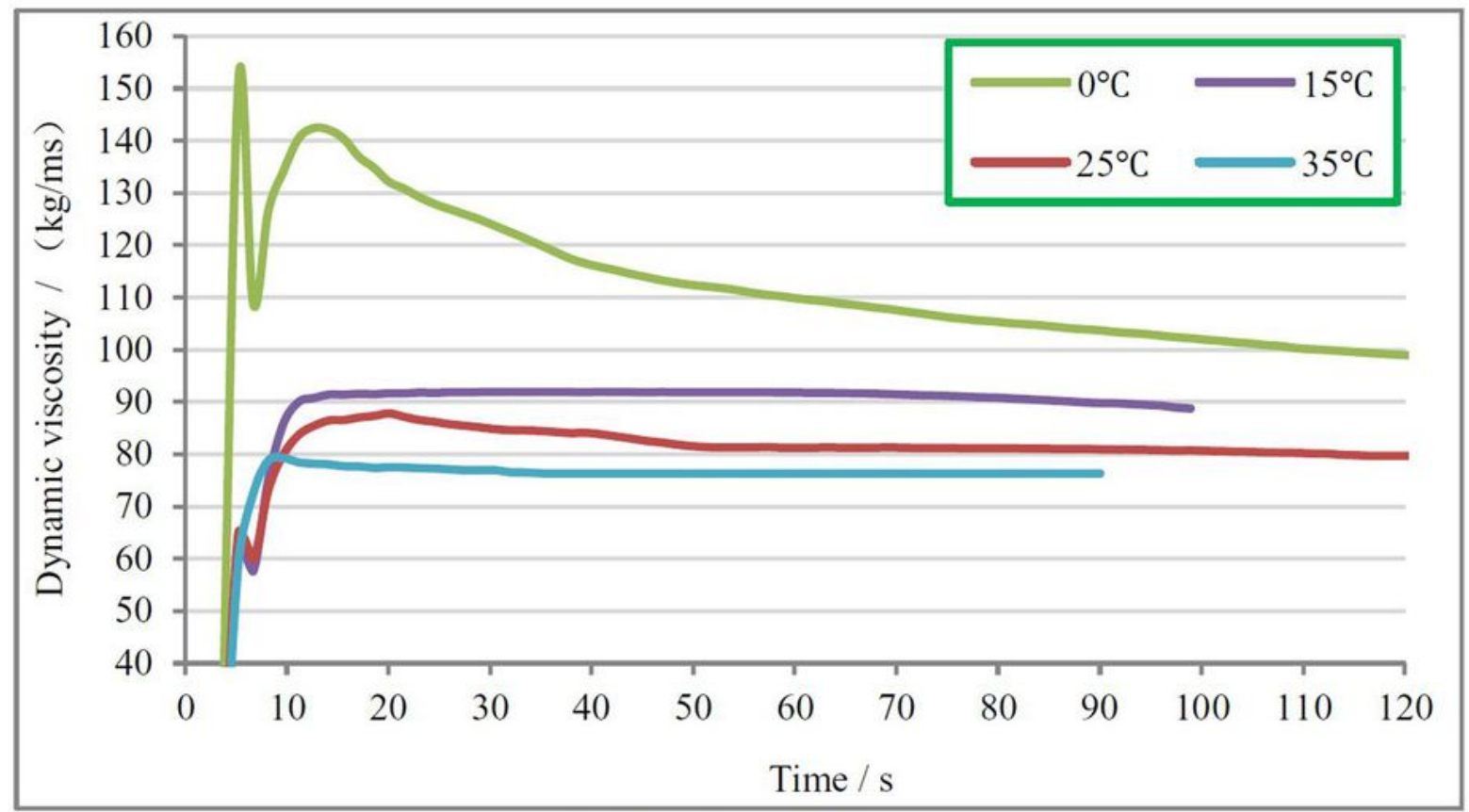

(b) Experimental data

\section{Figure 18}

Determination of sediments dynamic viscosity 


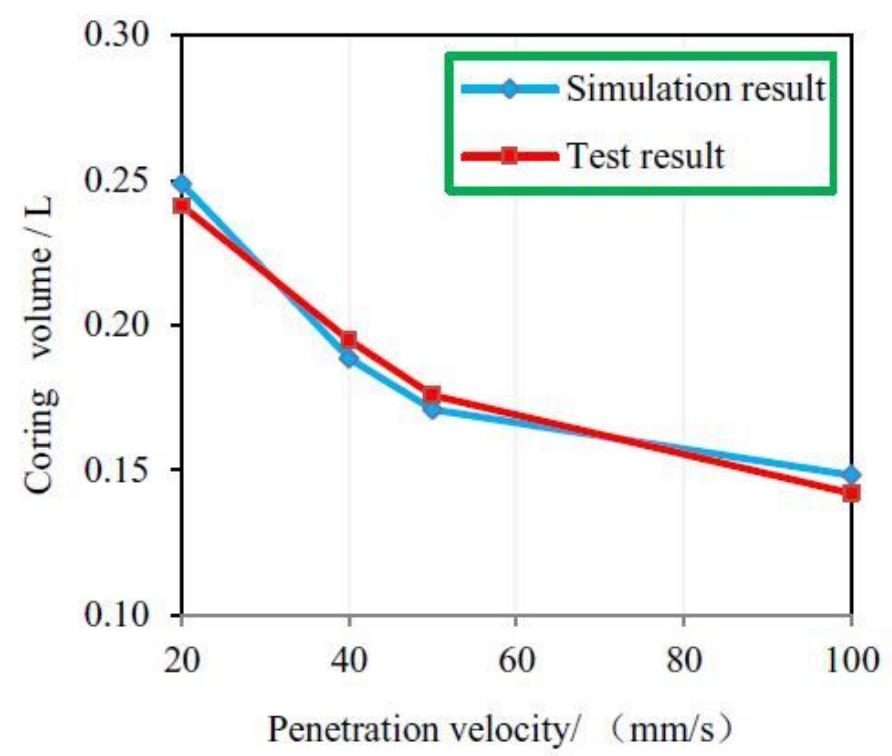

(a)

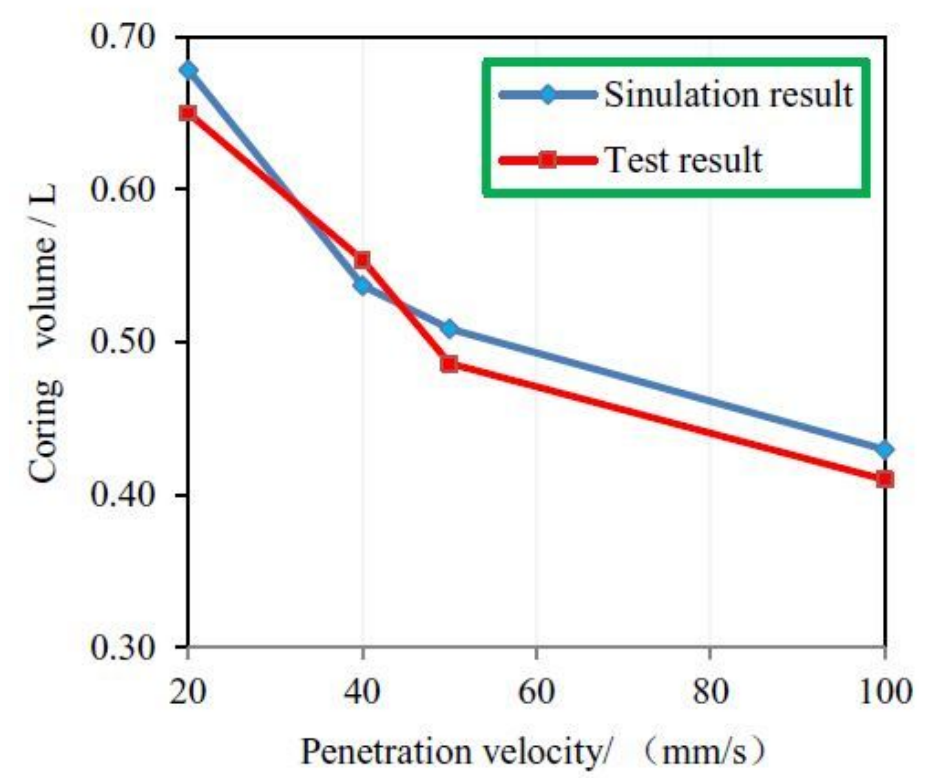

(c)

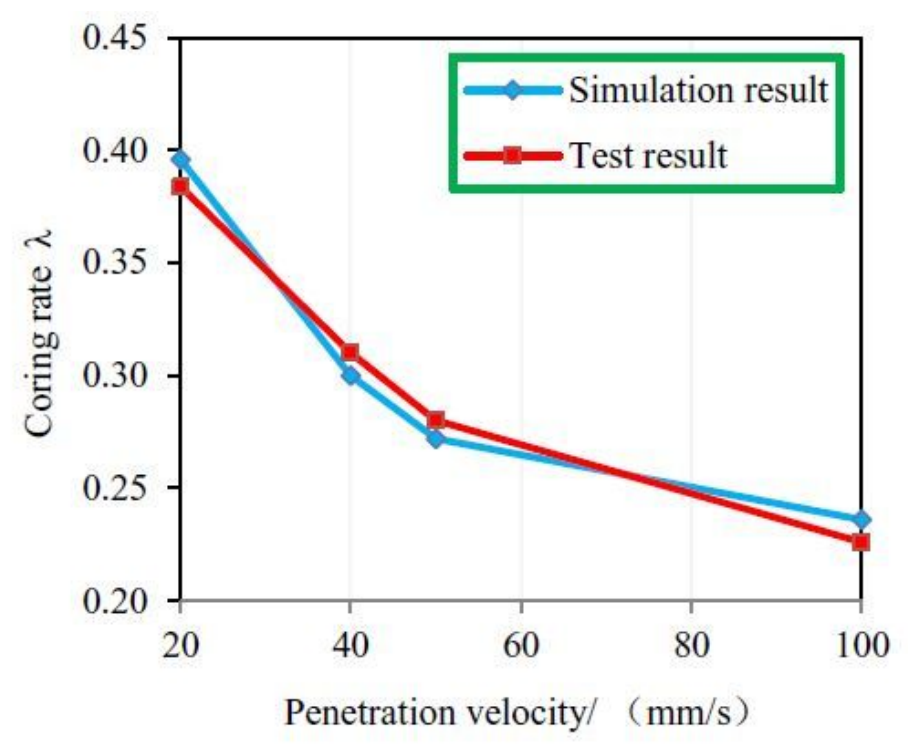

(b)

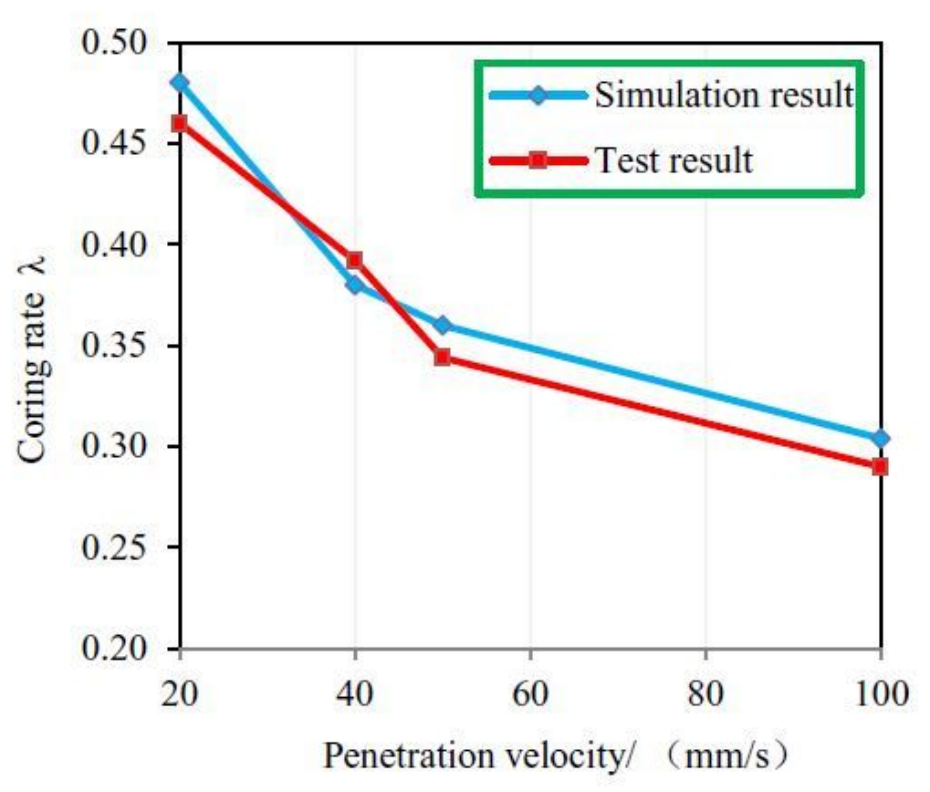

(d)

Figure 19

Comparison of simulation and experimental results 